\title{
PALEO
}

Revue d'archéologie préhistorique

\section{Diversité des techniques employées lors de la confection des encoches et des denticulés moustériens de Mauran (Haute-Garonne, France)}

Diversity of techniques used for the making of Mousterian notches and denticulates at Mauran (Haute-Garonne, France)

Céline Thiebaut, Jacques Jaubert, Vincent Mourre et Hugues Plisson

\section{OpenEdition Journals}

Édition électronique

URL : http://journals.openedition.org/paleo/1921

DOI : $10.4000 /$ paleo.1921

ISSN : 2101-0420

Éditeur

SAMRA

Édition imprimée

Pagination : 75-106

ISSN : $1145-3370$

\section{Référence électronique}

Céline Thiebaut, Jacques Jaubert, Vincent Mourre et Hugues Plisson, « Diversité des techniques employées lors de la confection des encoches et des denticulés moustériens de Mauran (HauteGaronne, France) », PALEO [En ligne], Numéro spécial | 2009-2010, mis en ligne le 24 avril 2012, consulté le 07 juillet 2020. URL : http://journals.openedition.org/paleo/1921 ; DOI : https://doi.org/ 10.4000/paleo.1921

\section{cc) (1)}

PALEO est mis à disposition selon les termes de la licence Creative Commons Attribution - Pas d'Utilisation Commerciale - Pas de Modification 4.0 International. 


\title{
DIVERSITÉ DES TECHNIQUES EMPLOYÉES LORS DE LA CONFECTION DES ENCOCHES ET DES DENTICULÉS MOUSTÉRIENS DE MAURAN (Haute-Garonne, France)
}

\author{
Céline THIÉBAUT ${ }^{(1)}$, Jacques JAUBERT (2), \\ Vincent MOURRE ${ }^{(3)}$ et Hugues PLISSON ${ }^{(1)}$
}

\begin{abstract}
Résumé : Les vestiges mis au jour à Mauran résultent d'un cumul de plusieurs occupations saisonnières de plein air liées principalement à une exploitation et une consommation monospécifique de bisons. L'industrie lithique, caractérisée par une grande diversité des matières premières, est rattachée à l'une des manifestations du Moustérien à denticulés.

L'étude des encoches et des denticulés montre une certaine variabilité morphologique des tranchants retouchés ainsi que des négatifs d'encoches (morphologie en section, en plan d'angle de l'encoche). Les tranchants n'ont donc pas les mêmes caractéristiques morphologiques et n'offrent pas les mêmes potentialités fonctionnelles. Ces particularités sont à mettre en relation avec les différentes techniques utilisées lors de leur confection. L'objectif de ce travail est de déterminer, par une approche technologique et expérimentale, les techniques à l'origine des caractéristiques très particulières des négatifs d'enlèvements observés sur les encoches et les denticulés archéologiques de Mauran.
\end{abstract}

Mots-clés : Mauran, Haute-Garonne, France, Moustérien, OIS 3, encoches et denticulés, techniques de confection, méthodologie, expérimentation.

Abstract: Diversity of techniques used for the making of Mousterian notches and denticulates at Mauran (Haute-Garonne, France). The archaeological evidence from Mauran Middle Paleolithic open-air site is the result of several consecutive seasonal occupations mainly related with Bison hunting. The lithic industry, characterized by the use of a large number of different raw materials, was related to the Denticulate Mousterian facies. The study of notches and denticulates reveals that the retouched edges and the notches negatives vary morphologically up to a point. Therefore, all the cutting edges do not have the same morphological characteristics and do not show the same functional potential. Those special features should be related with the different techniques used for their making. The aim of this work is to determine, using a technological and experimental approach, which techniques led to the very special scar negatives shown by the Mauran archaeological notches and denticulates.

Key-words: Mauran, Haute-Garonne, France, Mousterian, OIS 3, notches and denticulates, making techniques, methodology, experimentation.

\section{Localisation du site et historique des fouilles}

Le gisement de plein air de Mauran est adossé à une barre rocheuse calcaire qui appartient à l'un des chaînons prépyrénéens : le massif oriental des Petites Pyrénées. Situé à une soixantaine de kilomètres au sud de Toulouse (Haute-Garonne), il domine la vallée de la Garonne sur sa rive droite (fig. 1).

Cette implantation privilégiée autorise notamment : - le contrôle d'une voie de passage, donc la possibilité d'être près du parcours de grands herbivores caractérisés par des migrations saisonnières et un comportement grégaire ; - une disponibilité locale de matières premières lithiques ; - une proximité avec un point d'eau douce (Geneste et Jaubert 1999 ; Rendu 2007).

Découvert en 1972 par M. Orliac, ce gisement a été fouillé sous la direction de C. Farizy de 1976 à 1981 et l'industrie lithique a été étudiée par J. Jaubert (Jaubert 1993 ; Farizy et al. 1994). Plusieurs sondages ont été réalisés afin d'évaluer l'étendue du gisement ; les tranchées de 1976 et l'exploration de la coupe de 1981 sur $80 \mathrm{~m}$ de front et sur $10 \mathrm{~m}$ vers

(1) Université de Provence, UMR 6636-MMSH-ESEP - 5 rue du Château de l'Horloge - 13094 Aix-en-Provence cedex 02 celine.thiebaut@wanadoo.fr - plisson@mmsh.univ-aix.fr

(2) Université Bordeaux 1, UMR 5199 - IPGQ/PACEA - Avenue des Facultés - 33405 Talence cedex -

j.jaubert@ipgq.u-bordeaux1.fr

(3) Université Toulouse le Mirail, UMR 5688 - TRACES - 5, Allées Antonio machado - 31058 Toulouse cedex 9 -

vincent.mourre@wanadoo.fr 


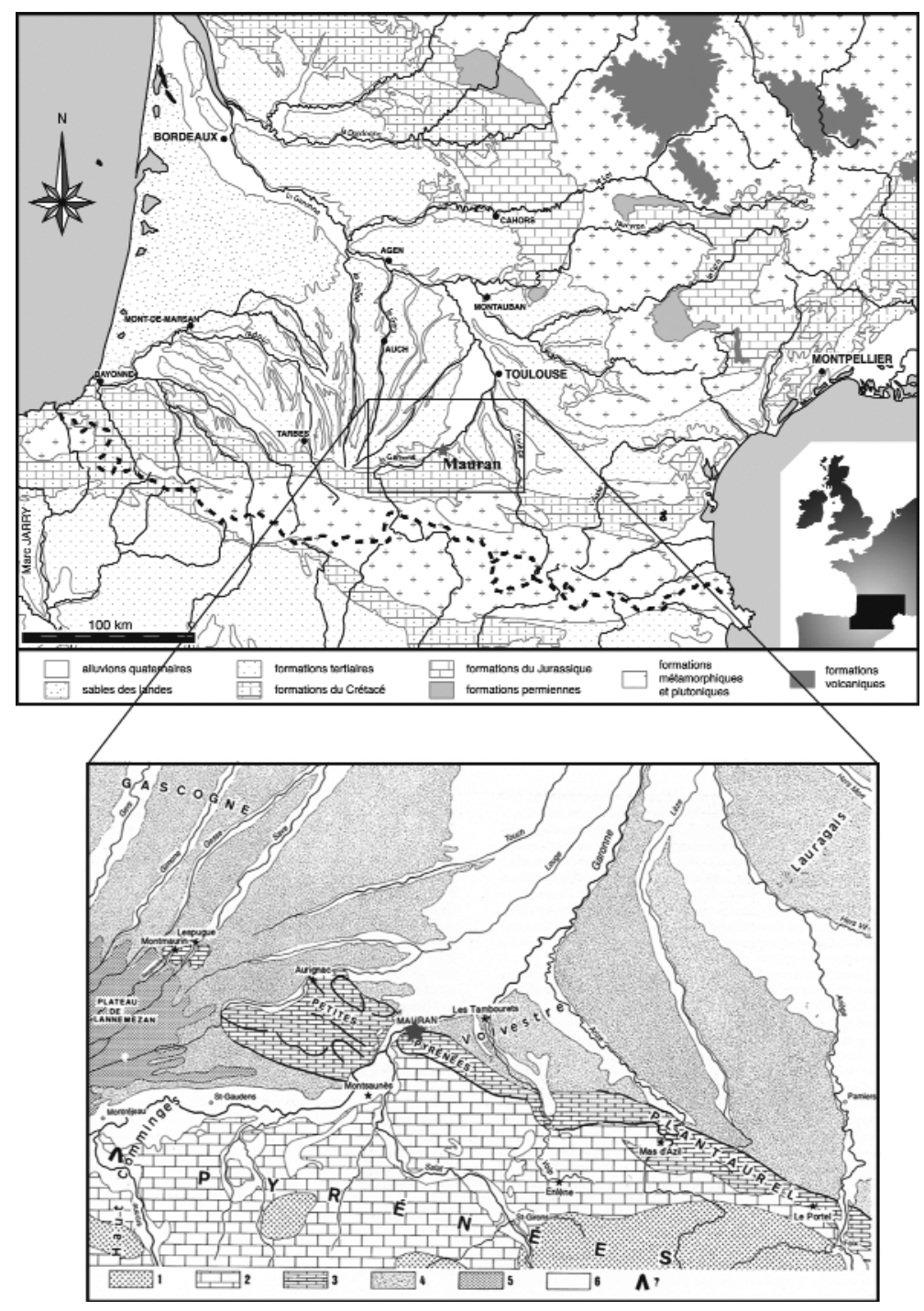

Figure 1 - Localisation du gisement de Mauran (Haute-Garonne).

Figure 1 - Location of Mauran site (Haute-Garonne).

l'ouest, ont révélé une étendue du site proche de $1000 \mathrm{~m}^{2}$. Plusieurs secteurs furent fouillés à 20,30 et $60 \mathrm{~m}$ du secteur principal et dans tous les cas, les niveaux archéologiques repérés et fouillés étaient comparables au secteur principal en termes de densité et de contenu (op. cit.).

\section{Analyse stratigraphique et mise en place du gisement}

L'analyse stratigraphique réalisée par V. Krier décrit le gisement comme une " accumulation détritique, épaisse au moins de $9 \mathrm{~m}$, et constituée d'une alternance de dépôt limono-argileux de couleur verte, brune ou rouille et de formation soit de cailloutis, soit de gros blocs calcaires. " (Krier in Farizy et al. 1994 p. 29). Au sein de cette accumulation, deux ensembles archéologiques ont été individualisés ( $\mathrm{C} 1$ niveau XV6 et $\mathrm{C} 2$ niveau XV2, fig. 2).

Ces deux niveaux archéologiques pourraient avoir représenté, à l'origine, un seul ensemble affecté par un jeu complexe de flexures entraînant des déplacements verticaux du niveau initial. Cette unité a également pu subir un glissement de terrain, " tout en conservant les relations de proximité des objets entre eux " (Girard et al. 1975 - p.179).

L'étude taphonomique des vestiges osseux et lithiques permet de conclure que les perturbations au sein de l'accumulation sont faibles : "les ossements ont été brisés sous le poids des sédiments et ont souvent été étirés dans l'argile qui a subi de faibles déplacements latéraux et de nombreuses flexures après le dépôt archéologique. Cependant l'analyse des plans et les nombreux remontages lithiques qui ont pu être faits malgré la faible surface fouillée montrent que l'ensemble a été peu perturbé. » (Farizy et al. 1994 - p. 239).

\section{Datation}

Pour des raisons d'étagement des formations alluviales, l'âge de la séquence ne peut être antérieur au Dernier Interglaciaire. Les quelques éléments de biochronologie ne contredisent pas cette estimation. Une série de datations ESR a été obtenue par R. Grün à partir d'échantillons den- 


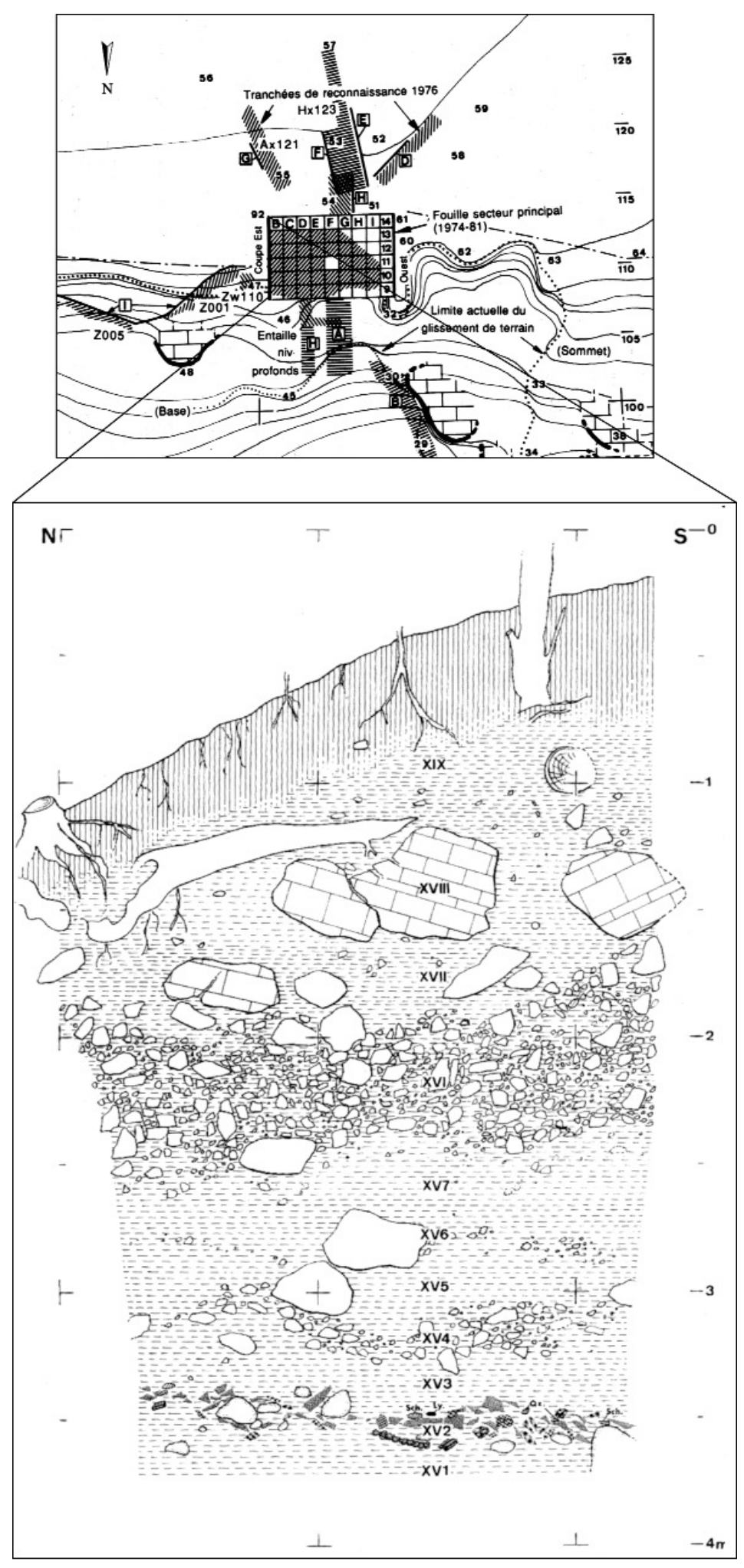

Figure 2 - Stratigraphie de Mauran

(relevé Jaubert et Mourre, in Jaubert et al. 1996).

Figure 2 - Stratigraphy of Mauran

(by Jaubert and Mourre, in Jaubert et al. 1996). taires du niveau principal ; elles s'échelonnent entre $31700 \pm 2100$ et $47400 \pm 3400 \mathrm{BP}$, donnant un âge moyen de $44 \pm 3$ ka BP (Grün in Farizy et al. 1994). Si les différentes études ne permettent pas d'être catégorique, un âge contemporain de l'interpléniglaciaire (OIS 3) est généralement admis pour Mauran (Jaubert et Bismuth 1996).

\section{Les vestiges paléontologiques}

La faune mise au jour dans le secteur principal se compose presque exclusivement de restes de Bison (98,97\%) auxquels s'ajoutent quelques fragments d'os de Cheval $(0,88 \%)$ et de Cerf $(0,12 \%)$.

L'état de conservation de certains vestiges fauniques attesterait un enfouissement non immédiat, mais constitué par étapes successives sur une longue période (Farizy et al. 1994). L'analyse des vestiges osseux de Bison montre que l'accumulation des carcasses s'est effectuée au cours de plusieurs occupations entre l'été et l'automne.

\section{L'industrie lithique}

L'industrie lithique de Mauran a fait l'objet de publications et de travaux détaillés (Girard et al. 1975 ; Jaubert 1993 ; Farizy et al. 1994 ; Jaubert et Mourre 1996 ; Thiébaut 2001) dont nous nous contenterons de rappeler les grandes lignes.

Les matières premières utilisées à Mauran proviennent pour l'essentiel d'un environnement local. La diversité des matières premières représentées est importante. On retrouve par ordre d'importance décroissante (en nombre de vestiges), des quartzites, silex, quartz, schistes, quartzites micacés, schistes à andalousite (cornéennes), gneiss, leptynites, granites, lydiennes, micaschistes, cherts, roches éruptives cristallines, roches métamorphiques très siliceuses, roches vertes (ophite, serpentine), roches sédimentaires détritiques et microgranites. Cette diversité des matières premières ne se traduit pas par une diversité aussi prononcée en ce qui concerne les schémas de production mis en œuvre. En effet, les principales matières premières utilisées pour la confection d'outils bruts ou retouchés (quartzites, silex, quartz, schistes à andalousite et lydienne) ont été exploitées suivant les mêmes schémas de production : mise en œuvre principalement d'un débitage Discoïde pour la production d'éclats à dos débordant et de pointes pseudo-Levallois, complétée ponctuellement par un débitage sur enclume. Les supports obtenus sont restés bruts 
ou ont été transformés en denticulés, en coches et, de manière plus anecdotique, en racloirs. Parallèlement à la production de cet outillage léger, un outillage lourd composé de galets aménagés ou percutés a été réalisé.

Quatre séquences ont pu être distinguées au sein du schéma opératoire (Jaubert 1993 ; Farizy et al. 1994 ; Geneste et Jaubert 1999) :

- acquisition de galets bruts sélectionnés pour leur dureté, leur module ou leur masse et utilisés comme percuteurs (ou enclumes) ou pour des activités domestiques (boucherie) ; - acquisition, essentiellement de galets de quartzite et schiste à andalousite, pour l'aménagement de tranchants de type choppers. Certains galets, et plus particulièrement les galets en quartzite micacé et en schiste ont été très probablement fractionnés sur enclume (fig. 3 - en annexe);

- acquisition de galets, puis mise en forme et production de supports spécifiques (éclats, pointes pseudo-Levallois) selon un mode principalement Discoïde, unifacial ou bifacial (fig. 4 et 5 - en annexe) ;

- même schéma poursuivi par la confection de supports retouchés. Cette production d'outils retouchés concerne essentiellement le silex et le quartzite, exceptionnellement le quartz et plus rarement la lydienne. Les outils retouchés sont principalement des encoches et des denticulés.

Les supports retouchés, au nombre de 116, représentent $9,8 \%$ des éclats et sont dominés par les denticulés et les encoches $(62,9 \%)$, nettement plus fréquents que les racloirs $(17,2 \%)$.

Les encoches et les denticulés sont produits majoritairement sur des supports en silex puis en quartzite, plus rarement sur quartz, schiste à andalousite, gneiss et autres roches métamorphiques siliceuses.

Tandis que les encoches sont principalement clactoniennes ( $n=22 / 24$, fig. 6 - en annexe), trois types de denticulés sont présents (Thiébaut 2005) :

- denticulés à macrodenticulation, $\mathrm{n}=13$ (fig. 7 - en annexe), dont trois doubles et trois autres qui dégagent un saillant (fig. 8 - en annexe) ;

- denticulés à moyenne denticulation, $n=22$ (fig. 9 - en annexe) dont deux doubles ;

- denticulés à microdenticulation, $n=13$ (fig. 10 - en annexe) ;

- denticulé double à moyenne et microdenticulation, $n=1$; - pointe de Tayac, $n=1$ fragment.

\section{Les techniques de retouche des pièces encochées}

L'importante diversité morphologique des denticulés de Mauran nous a conduits à nous interroger sur les techniques de retouche employées.

Depuis les travaux précurseurs de L. Henri-Martin (1906), de nombreux chercheurs ont démontré que des matériaux très divers pouvaient être utilisés comme retouchoirs (pier- re dure, pierre tendre, bois végétal et animal...) (p.ex. Tixier et al. 1980). Plusieurs chercheurs ont attiré l'attention sur l'importance des gestes effectués lors de la retouche (percussion directe perpendiculaire ou trajectoire rectiligne, percussion directe tangentielle ou trajectoire curviligne, trajectoire à infléchissement, pression, égrisage, etc. (cf. notamment Bourguignon 1997 et Pelegrin 2004) ainsi que sur la morphologie et les propriétés physiques et mécaniques des percuteurs. Ce dernier auteur décrit notamment la morphologie de la surface active du percuteur, désignée par le terme " touche », emprunté au vocabulaire de la technologie des outillages modernes. Les touches des percuteurs qu'il décrit sont convexes ou planes.

Des techniques plus originales ont été décrites, dont la retouche par percussion à partir du bulbe d'un éclat (travaux de S.A. Semenov et V.E. Shchelinskiï, cf. Plisson 1988 ; Tixier 2000), la retouche par pression avec les dents chez les aborigènes d'Australie (Gould et al. 1971). L'hypothèse de l'utilisation de grattoirs circulaires au Néolithique pressignien (Berthouin 1963) ou de l'angle de chasse d'éclat au Solutréen supérieur (Cheynier 1944) a aussi été avancée de même que la retouche à l'aide d'un tranchant d'éclat (Escalon de Fonton 1979 ; Bocquet 1980 ; Pelegrin 1995). L'utilisation d'un tranchant d'éclat pour la confection par pression de denticulés à microdenticulation a été identifiée au sein d'industries diverses, du Paléolithique moyen jusqu'au Néolithique (Deffarges et Sonneville-Bordes (de) 1972 ; Pelegrin op. cit ; Bourguignon et al. 2000 ; Plisson in litteris). À ce jour, l'utilisation d'un tranchant par percussion directe semble plus rarement signalée. Seuls les travaux en cours de J. Airvaux et F. Lévêque, concernant l'industrie châtelperronienne du niveau 8 de Chez-Pinaud à Jonzac en Charente-Maritime, ont mis en évidence l'emploi de cette technique pour la confection de denticulés (Airvaux comm. pers., mars 2004). II convient également de mentionner pour mémoire que, selon L. Leakey, les caractéristiques des «pièces esquillées " d'Afrique orientale pouvaient résulter de leur utilisation comme retouchoirs (Leakey 1931 cité par Chauchat et al. 1985).

La présente étude se propose de mettre en évidence l'emploi en percussion directe au Paléolithique moyen de percuteurs à touches dièdres (tranchant d'éclat, galets plats fractionnés longitudinalement sur enclume, etc. $)^{4}$.

\section{Approche expérimentale}

\section{Protocole}

Afin de tester l'éventuelle corrélation entre la technique utilisée et les types de denticulés présents à Mauran, nous avons confectionné 12 encoches simples, 16 denticulés à macrodenticulation, 9 denticulés à moyenne denticulation et 30 denticulés à microdenticulation (tabl. 1), tous en silex et selon différentes techniques utilisant des percuteurs en pierre dure ou en matière dure animale (tabl. 2 et fig. 11 en annexe).

(4) L'emploi de l'adjectif « dièdre » dans ce contexte est emprunté à R. Scandiuzzi. 


\begin{tabular}{|l|c|c|}
\cline { 2 - 3 } \multicolumn{1}{c|}{} & outils $\mathbf{n}=$ & encoches $\mathbf{n}=$ \\
\hline encoches simples & 12 & 12 \\
\hline denticulés à macrodenticulation & 16 & 53 \\
\hline denticulés à moyenne denticulation & 9 & 42 \\
\hline denticulés à microdenticulation & 30 & 276 \\
\hline \multicolumn{1}{|c|}{ Total } & $\mathbf{6 7}$ & $\mathbf{3 8 3}$ \\
\hline
\end{tabular}

Tableau 1 - Nombre de pièces expérimentales confectionnées.

Table 1 - Number of experimental pieces produced.

\begin{tabular}{|c|c|c|c|c|c|}
\hline $\begin{array}{l}\text { touche du } \\
\text { percuteur }\end{array}$ & type du percuteur & geste & encoches & denti. macro. & denti. moyenne \\
\hline \multirow{4}{*}{ 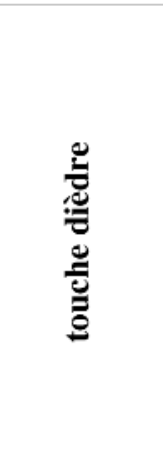 } & $\begin{array}{c}\text { tranchant d'éclat en } \\
\text { quartzite } \\
\text { galet splités en quartzite }\end{array}$ & $\begin{array}{l}\text { tangentiel } \\
\text { perpendiculaire } \\
\text { pression dormant } \\
\text { tangentiel } \\
\text { perpendiculaire }\end{array}$ & $\begin{array}{l}- \\
- \\
- \\
1 \\
2\end{array}$ & $\begin{array}{l}1 \\
- \\
- \\
- \\
2\end{array}$ & $\begin{array}{l}2 \\
- \\
- \\
- \\
-\end{array}$ \\
\hline & \multirow{2}{*}{$\begin{array}{l}\text { fragment de diaphyse de } \\
\text { bœuf }\end{array}$} & tangentiel & - & 1 & 1 \\
\hline & & $\begin{array}{l}\text { perpendiculaire } \\
\text { arrachement }\end{array}$ & $\begin{array}{l}- \\
-\end{array}$ & $\begin{array}{l}1 \\
-\end{array}$ & $\begin{array}{l}- \\
-\end{array}$ \\
\hline & tranchant d'éclat en silex & pression dormant & - & - & - \\
\hline \multicolumn{3}{|c|}{ Total } & 3 & 5 & 3 \\
\hline \multirow{5}{*}{ 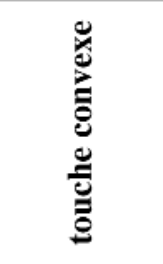 } & galet en quartzite & $\begin{array}{l}\text { tangentiel } \\
\text { perpendiculaire }\end{array}$ & $\begin{array}{l}4 \\
-\end{array}$ & $\begin{array}{l}6 \\
2\end{array}$ & $\begin{array}{l}1 \\
-\end{array}$ \\
\hline & \multirow{2}{*}{ galet en granite } & tangentiel & - & 1 & - \\
\hline & & perpendiculaire & 4 & 1 & 4 \\
\hline & galet en grès & perpendiculaire & - & - & 1 \\
\hline & galet en silex & perpendiculaire & 1 & 1 & - \\
\hline \multicolumn{3}{|c|}{ Total } & 9 & 11 & 6 \\
\hline & & Total & 12 & 16 & 9 \\
\hline
\end{tabular}

Tableau 2 - Techniques utilisées pour la confection des encoches et des denticulés expérimentaux.

Table 2 - Techniques used for the production of experimental notches and denticulate.

Caractéristiques des négatifs des encoches selon le type de percuteur utilisé

Les encoches et les coches des denticulés, réalisées en un seul coup, présentent des types d'impacts différents et des morphologies variées (fig. 12 à 16 - en annexe).

L'utilisation d'un percuteur à touche convexe et ce, quelle que soit la trajectoire qu'il effectue, produit principalement des encoches présentant un impact diffus $(40,6 \%)$ ou localisé $(45,8 \%)$, parfois trop esquillé pour être identifiable $(13,6 \%)$. Les encoches confectionnées avec des percuteurs à touche dièdre présentent en revanche des impacts ponctuels $(61,0 \%)$ ou localisés $(33,3 \%)$ mais rarement diffus $(2,5 \%$, fig. 17 - en annexe). Une encoche retouchée a été produite sur un tranchant aigu $\left(30^{\circ}\right)$ en un seul coup de percuteur (fig. 14, $n^{\circ} 1$ - en annexe).

La morphologie de l'encoche semble également varier en fonction du type de percuteur utilisé. En effet, alors que I'utilisation d'un percuteur à touche convexe pro- duit des encoches dont la morphologie est principalement arrondie, celles confectionnées par des percuteurs à touche dièdre présentent majoritairement des morphologies arrondies mais aussi en « $V$ » (fig. 18 - en annexe).

D'autres différences peuvent être mises en évidence à l'aide de critères métriques tels que la longueur d'ouverture de l'encoche et la distance entre les coches des denticulés (fig. 19 - en annexe).

Les denticulés à microdenticulation présentent des coches dont les longueurs d'ouvertures sont différentes selon le type de percuteur utilisé et le geste employé (fig. 20 - en annexe). Les coches des denticulés confectionnés avec des percuteurs à touche convexe présentent des longueurs moyennes d'ouvertures nettement supérieures à celles des coches confectionnées avec un percuteur à touche dièdre. Les gestes d'arrachement et de pression permettent l'obtention de coches très étroites. 
De façon similaire, la distance entre les coches des denticulés à microdenticulation sera plus importante pour les denticulés confectionnés à l'aide d'un percuteur à touche convexe que pour ceux confectionnés avec un percuteur à touche dièdre. La grande précision que procure un geste d'arrachement ou une pression sur un tranchant permet d'obtenir des coches très proches les unes des autres (fig. 21 - en annexe).

Caractéristiques des encoches et des coches des denticulés de Mauran

Les encoches de Mauran présentent principalement un impact diffus ou localisé arrondi, rarement ponctuel et des morphologies arrondies, rarement rectilignes ou en « $V$ » (fig. 22 et 23 - en annexe). L'ouverture des encoches est majoritairement supérieure à $5 \mathrm{~mm}$ (fig. 24 - en annexe). De fait, la grande majorité d'entre elles a certainement été produite avec un percuteur à touche convexe (fig. $25, n^{\circ} 1$ et 4 à 6 en annexe). Cependant, la présence d'un petit nombre d'encoches comportant un impact ponctuel et dont la longueur d'ouverture est inférieure à $3 \mathrm{~mm}$ pourrait attester l'utilisation de percuteurs à touche dièdre (fig. $25 n^{\circ} 2$ et 3 - en annexe).

Les coches des denticulés à moyenne et macrodenticulation ont un impact principalement localisé avec une morphologie arrondie, puis diffus de morphologie rectiligne ou arrondie (fig. 22 et 23 et fig. $30 n^{\circ} 1$ et 3 et fig. 31 - en annexe). Les denticulés à microdenticulation présentent majoritairement des impacts ponctuels et de morphologie en « $V$ » ou arrondie (fig. $30, n^{\circ} 2$, fig. $32, n^{\circ} 1$ et 2 - en annexe), parfois localisés arrondis (fig. $32 n^{\circ} 4$ et 6 ), plus rarement diffus (fig. 22 et 23 - en annexe). Au sein des denticulés à microdenticulation, les encoches ont une ouverture moyenne inférieure à $4 \mathrm{~mm}$ (fig. 26 et 28 - en annexe) associées à des distances entre les encoches de moins de $5 \mathrm{~mm}$ en moyenne (fig. 27 et 29 -en annexe). Ces dimensions semblent se rapprocher de celles obtenues avec un percuteur à touche dièdre utilisé en percussion directe, perpendiculairement ou tangentiellement.

L'utilisation d'un ou plusieurs percuteurs à touche convexe, selon une trajectoire tangentielle ou perpendiculaire, semble attestée par la présence de nombreuses encoches au point d'impact localisé ou diffus, généralement arrondi, et par la présence de denticulés à macro et moyenne denticulation.

L'utilisation de percuteurs à touche dièdre semble également envisageable, principalement pour la confection de denticulés à microdenticulation. La nature exacte de ce percuteur à touche dièdre reste difficile à déterminer et il est malaisé de trancher entre l'utilisation d'un galet fractionné sur enclume ou celle d'un tranchant d'éclat.

Cependant, certains galets fractionnés sur enclumes présentent un léger émoussé du tranchant et un piquetage sur le plan d'intersection entre la surface naturelle et celle débitée. Ces stigmates ne se retrouvent pas sur des galets expérimentaux non utilisés mais sont présents de façon plus soutenue sur ceux utilisés pour la confection des denticulés expérimentaux. II était tentant de voir dans ces galets les
« retouchoirs à denticulés ». Toutefois, un premier examen réalisé à la loupe binoculaire semble indiquer que les stigmates des pièces archéologiques et expérimentales ne sont pas de même nature. Pour les galets de Mauran (fig. 33 - en annexe), le piquetage est très prononcé tandis que sur les galets expérimentaux, l'émoussé est beaucoup plus marqué (fig. 34 - en annexe). Si ces galets fractionnés en split ont probablement été utilisés en percussion sur un matériau dur, leur fonction précise reste pour l'instant indéterminée.

\section{CONCLUSION}

L'approche expérimentale mise en œuvre pour faciliter la reconnaissance des techniques utilisées pour la production des encoches et des denticulés de Mauran par les groupes humains préhistoriques, montre l'existence d'une corrélation entre, d'une part, le type de percuteur employé et le geste effectué et, d'autre part, les différentes caractéristiques morphologiques et métriques des encoches. En effet, les encoches confectionnées par des percuteurs à touche convexe présentent généralement des impacts diffus ou localisés et des morphologies arrondies tandis que l'utilisation de percuteurs à touche dièdre permet d'obtenir des impacts ponctuels et des encoches présentant une morphologie en “ $V$ ». Les denticulés à microdenticulation n'auront pas non plus les mêmes caractéristiques métriques selon le type de percuteur et le geste effectué lors de leur confection.

Si les différents types de denticulés ne nécessitent pas systématiquement l'emploi de techniques distinctes (Arcysur-Cure, couches $\mathrm{H}$ et $\mathrm{G}$ de la Grotte du Bison et couche IVb1 de la grotte de l'Hyène), il semble que deux types de percuteur aient été utilisés pour la confection des denticulés à Mauran :

- un type de percuteur à touche convexe pour la fabrication de la majorité des encoches et des denticulés à macro et moyenne denticulation ;

- un type de percuteur à touche dièdre pour celle des denticulés à microdenticulation.

L'utilisation de cette dernière technique semble attestée par d'autres séries archéologiques (Saint-Césaire couche Egpf, La Borde ; Thiébaut 2005).

La mise en évidence d'une diversité des techniques de retouche au Paléolithique moyen peut sembler a priori relever de l'anecdote. Si elle découle directement d'un examen toujours plus attentif du matériel archéologique, elle conduit aussi à reconnaître aux artisans tailleurs moustériens une richesse comportementale jusqu'ici insoupçonnée. L'utilisation de plusieurs techniques lors de la confection d'encoche et de denticulés entraîne une diversité morphologique des produits encochés qui reflètent probablement des besoins diversifiés. L'une des conséquences de la présente analyse concerne également l'emploi du terme générique "denticulé » lors de décomptes typologiques : il apparaît que celui-ci regroupe artificiellement des outils très différents et qu'il masque d'une certaine façon une réalité plus complexe. 


\section{BIBLIOGRAPHIE}

BERTHOUIN F. 1963 - " Grattoirs discoïdes ayant servi de retouchoirs ", Les Amis du Musée Préhistorique du GrandPressigny, $\mathrm{n}^{\circ} 14$, pp. 13-14.

BOCQUET A. 1980 - « Le microdenticulé, un outil mal connu. Essai de typologie ", Bulletin de la Société Préhistorique Française, 77, fasc. 3, pp. 76-85.

BOURGUIGNON L. 1997 - Le Moustérien de type Quina : nouvelle définition d'une entité technique, Université de Paris X - Nanterre, Thèse de Doctorat, 672 p.

BOURGUIGNON L., ORTEGA I., BRENET M., LENOBLE A et ASTRUC L. 2000 - Saint-Denis-de-Pile - «Le gisement moustérien de Champs de Bossuet», Bordeaux, Document Final de Synthèse de Sauvetage Urgent, SRA Aquitaine, AFAN, ASF, vol. 1 : pp. 1-155 + vol. 2 : pp. 156-281.

CHAUCHAT C., NORMAND C., RAYNAL J.-P. ET SANTAMARIA R. 1985 - " Le retour de la pièce esquillée ! ", Bulletin de la Société Préhistorique Française, t. $82, \mathrm{n}^{\circ} 2$, pp. 35-41.

CHEYNIER dr. 1944 - « Retouchoirs en silex », Bulletin de la Société Préhistorique Française, t. XLI, n 1-2-3, pp. 49-50.

DEFFARGES R. ET SONNEVILLE-BORDES (de) D. 1972 "La scie, fossile directeur lithique du Magdalénien final ", Bulletin de la Société Préhistorique Française, t. 69, $n^{\circ} 5$, pp. 140-144.

ESCALON DE FONTON M. 1979 - « La retouche Montbani expérimentale ", Bulletin de la Société Préhistorique Française, 76 (7), pp. 217-220.

FARIZY C., DAVID F. ET JAUBERT J. 1994 - Hommes et bisons du Paléolithique moyen à Mauran (HauteGaronne), Paris, CNRS, XXXème supplément à Gallia Préhistoire, $267 \mathrm{p}$.

GENESTE J.-M. et JAUBERT J. 1999 - « Les sites paléolithiques à grands bovidés et les assemblages lithiques : chronologie, techno-économie et cultures ", in: Le bison : gibier et moyen de subsistance des hommes du Paléolithique aux Paléoindiens des grandes plaines, Brugal, J.-P., Enloe, J., David, F. et Jaubert, J., Eds., Antibes, Actes du Colloque international, Toulouse 1995, Editions ADPCA, pp. 185-214.

GIRARD C., HOFFERT M. et MISKOVSKY J.-C. 1975 "Gisements préhistoriques des petites Pyrénées. Contribution à la connaissance du Paléolithique moyen en Haute-Garonne : le gisement de Mauran», Bulletin de l'Association Française pour l'Etude du Quaternaire, 3-4, pp. 171-187.

GOULD R. A., KOSTER D. A. et SONTZ A. H. L. 1971 "The lithic assemblage of the Western Desert aborigines of Australia», American Antiquity, 36, n² 2, pp. 149-177.
HENRI-MARTIN L. 1906 - « Maillets ou enclumes en os provenant de la couche moustérienne de la Quina (Charente) ", Bulletin de la Société Préhistorique Française, t.III, pp. 155-159.

JAUBERT J. 1993 - « Le gisement paléolithique moyen de Mauran (Haute-Garonne) : techno-économie des industries lithiques ", Bulletin de la Société Préhistorique Française, t. $90, \mathrm{n}^{\circ}$ 5, pp. 328-335.

JAUBERT J. et BISMUTH T. 1996 - « Le Paléolithique moyen des Pyrénées centrales : esquisse d'un schéma chronologique et économique dans la perspective d'une étude comparative avec les documents ibériques ", In : $118^{\circ}$ Congrès National des Sociétés historiques et scientifiques, Pau, 1993, pp. 9-26.

JAUBERT J. et MOURRE V. 1996 - «Coudoulous, Le Rescoundudou, Mauran : diversité des matières premières et variabilité des schémas de production d'éclats ", In: Proceedings of the International Round table : Reduction processes ("chaînes opératoires») for the European Mousterian, Bietti, A. et Grimaldi, S., Eds., Rome, Quaternaria Nova VI, pp. 313-341.

JAUBERT J., MOURRE V. et DAVID F. 1996 - «Mauran (Balaresque) ", In : Bilan scientifique 1995 Direction Régionale des Affaires Culturelles Midi Pyrénées, Service Régional de l'Archéologie, Ministère de la culture, pp. 83-84.

LEAKEY L. S. B. 1931 - The Stone Age culture of Kenya colony, Cambridge, Cambridge University Press.

PELEGRIN J. 1995 - Technologie lithique : le Châtelperronien de Roc-de-Combe (Lot) et de La Côte (Dordogne), Paris, CNRS Editions, Cahiers du Quaternaire $\mathrm{n}^{\circ} 20,297$.

PELEGRIN J. 2004 - «Sur les techniques de retouche des armatures de projectile », In: Les derniers magdaléniens d'Étiolles, Pigeot, N. (Éd.), , XXXVllème supplément à Gallia Préhistoire pp. 161-166.

PLISSON H. 1988 - « Technologie et tracéologie des outils lithiques moustériens en Union Soviétique : les travaux de V. E Shchelinskiï ", In: L'Homme de Néandertal, vol. 4, La Technique, Binford, L. et Rigaud, J.-P., Eds., Liège, E.R.A.L, pp. 121-168.

RENDU W. 2007 - Planification des activités de subsistance au sein du territoire des derniers Moustériens : Cémentochronologie et approche archéozoologique de gisements du Paléolithique moyen (Pech-de-l'Azé I, La Quina, Mauran) et Paléolithique supérieur ancien (Isturitz), Université de Bordeaux 1, Thèse de Doctorat, $352 \mathrm{p}$.

THIÉBAUT C. 2001 - Caractérisation des encoches et des denticulés au Paléolithique moyen : Application d'une nouvelle méthode d'étude aux pièces encochées de Mauran (Haute-Garonne), Aix-en-Provence, Université de Provence, Mémoire de D.E.A, 232 p. 
THIÉBAUT C. 2003 - «Propositions terminologiques et méthodologiques pour l'étude des pièces encochées du Paléolithique moyen ", Préhistoire Anthropologie Mediterranéennes, 12, pp. 5-37.

THIÉBAUT C. 2005 - Le Moustérien à denticulés : Variabilité ou diversité techno-économique ? Université de Provence, Thèse de Doctorat, 2 volumes, $877 \mathrm{p}$.
TIXIER J. 2000 - « Outils moustériens à bulbe «piqueté» (Retaïma, Algérie) ", In: A la recherche de l'Homme Préhistorique, Mester, Z. et Ringer, Á. Eds., Liège, ERAUL 95, pp. 125-130.

TIXIER J., INIZAN M.-L., ROCHE H. et DAUVOIS M. 1980 Préhistoire de la pierre taillée - 1. terminologie et technologie, Paris, CREP, $120 \mathrm{p}$. 


\section{DIVERSITÉ DES TECHNIQUES EMPLOYÉES LORS DE LA CONFECTION DES ENCOCHES ET DES DENTICULÉS MOUSTÉRIENS DE MAURAN (Haute-Garonne, France)}

Céline THIÉBAUT, Jacques JAUBERT, Vincent MOURRE et Hugues PLISSON

\section{ANNEXES}



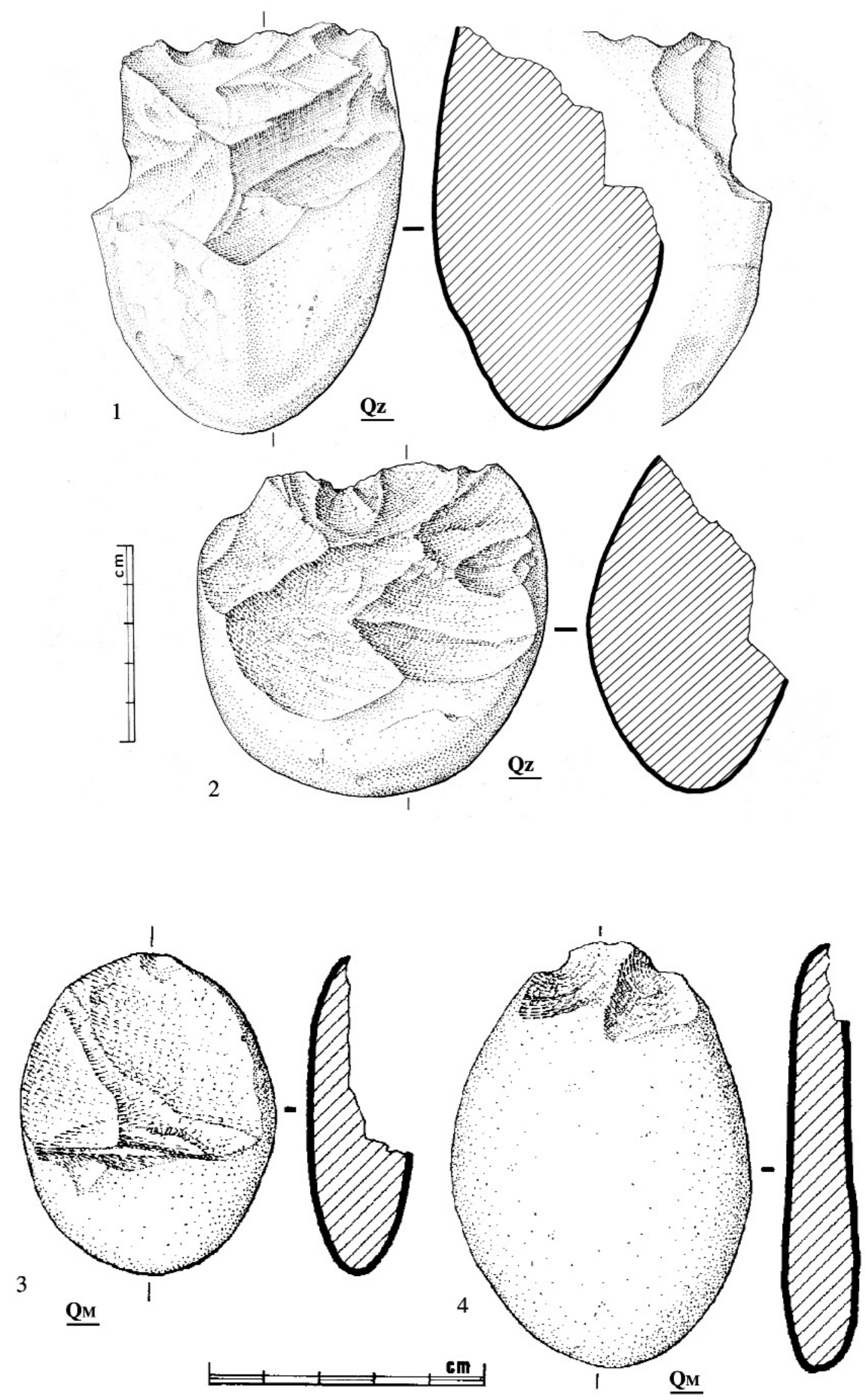

Figure 3 - 1, 2 et 4, galets aménagés en quartzite ; 3 galet en quartzite percuté sur enclume (galet splité) (Farizy et al.1994).

Figure 3-1, 2 et 4, quartite pebble tools ; 3 quartite split pebble on anvil (Farizy et al. 1994). 

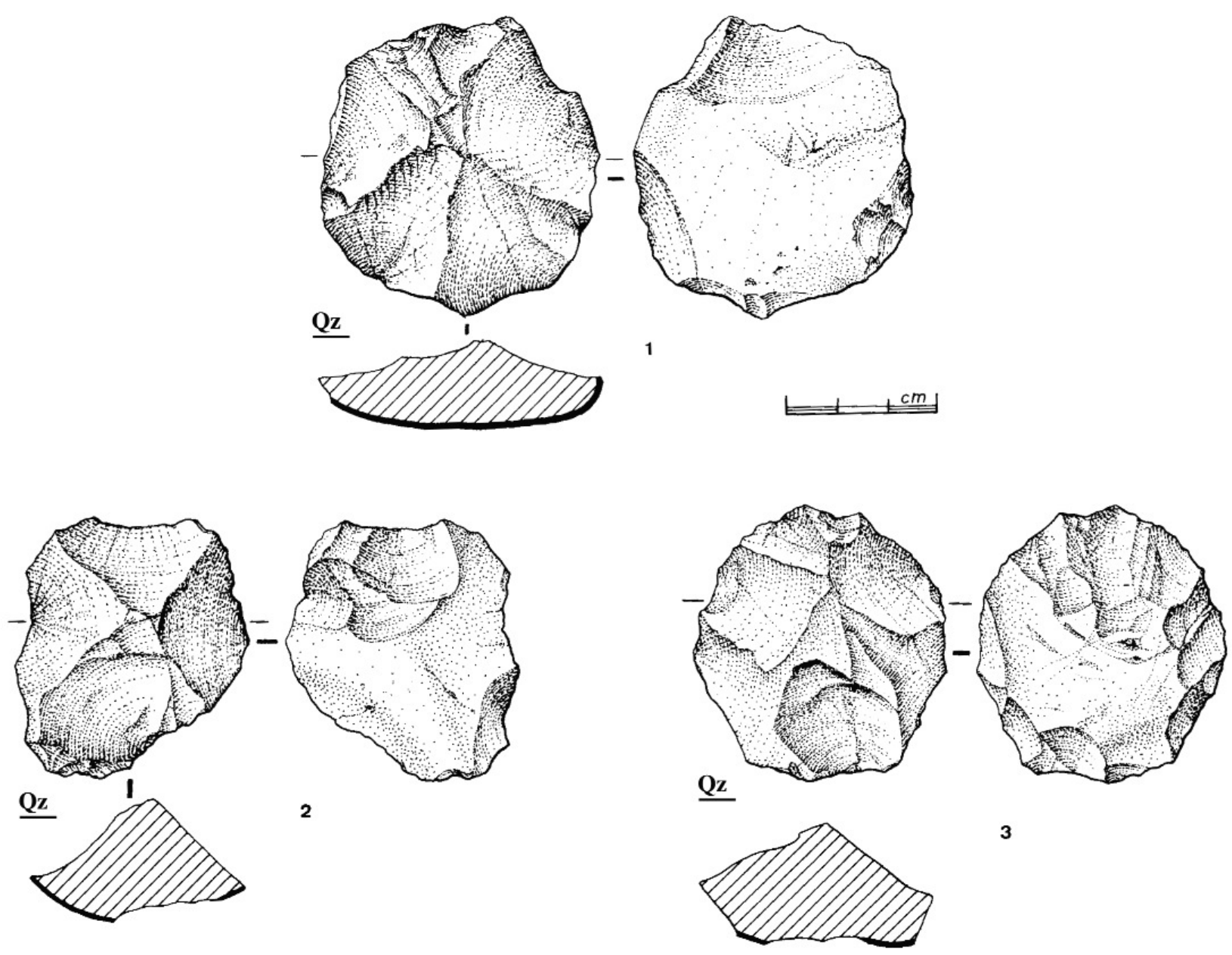

3

Figure 4 - Nucléus Discoïdes en quartzite (Farizy et al. 1994).

Figure 4 - Quartzite Discoid cores (Farizy et al. 1994). 

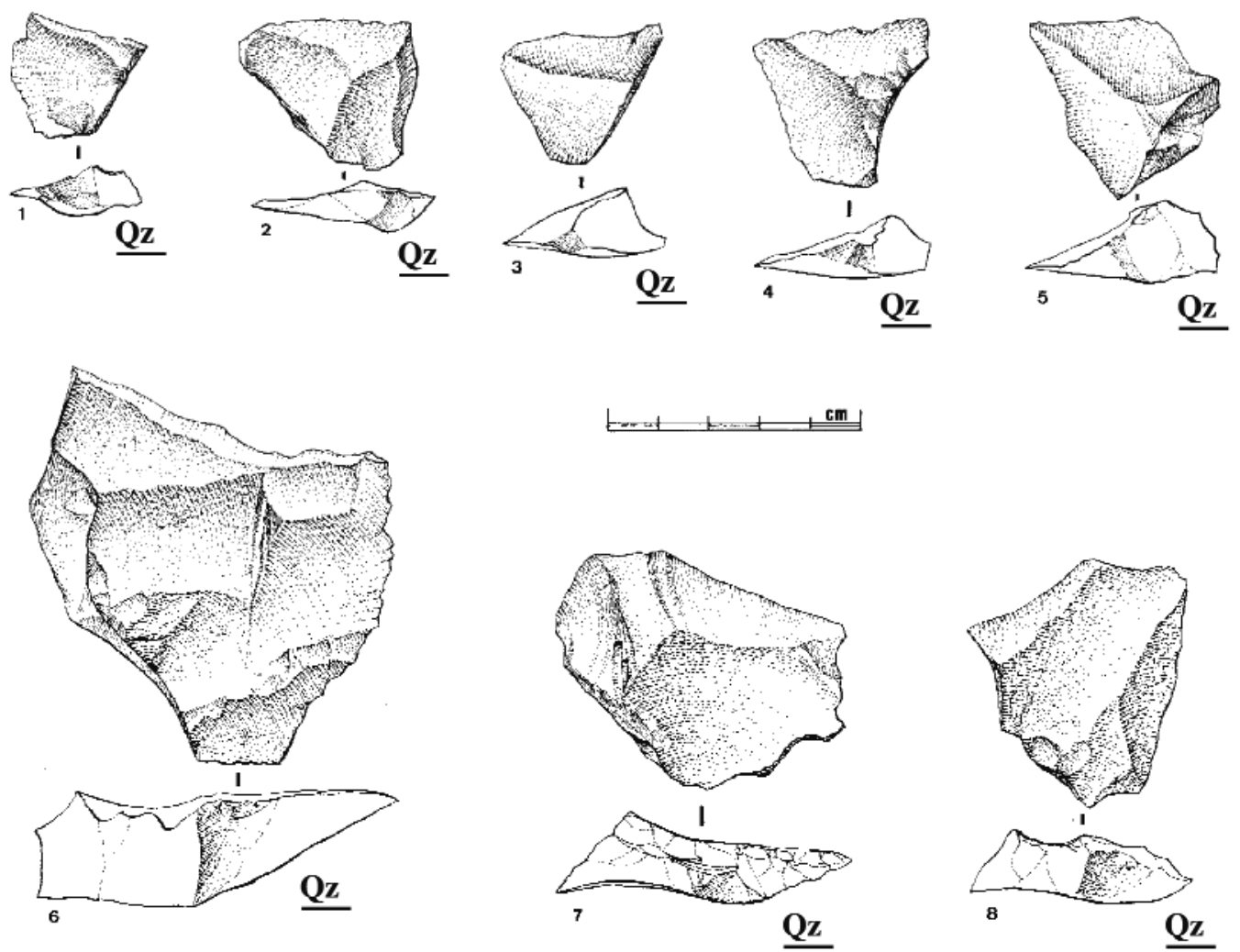

Figure 5 - Pointe pseudo-Levallois en quartzite (Farizy et al. 1994).

Figure 5 - Quartzite pseudo-Levallois point (Farizy et al. 1994). 


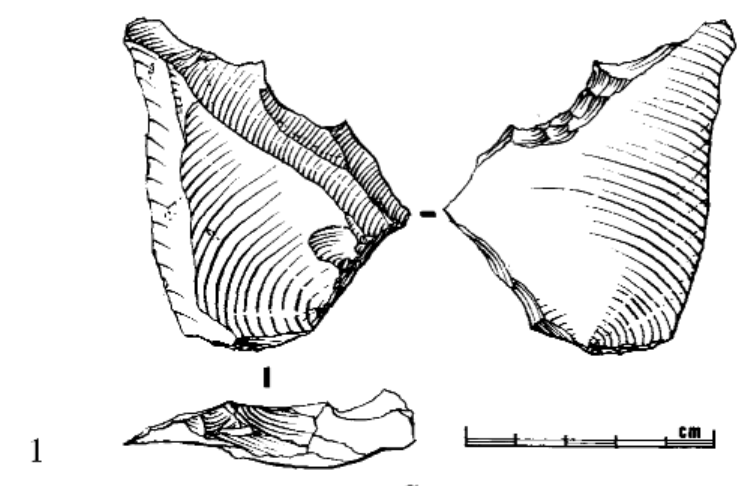

$\underline{\mathbf{S}}$
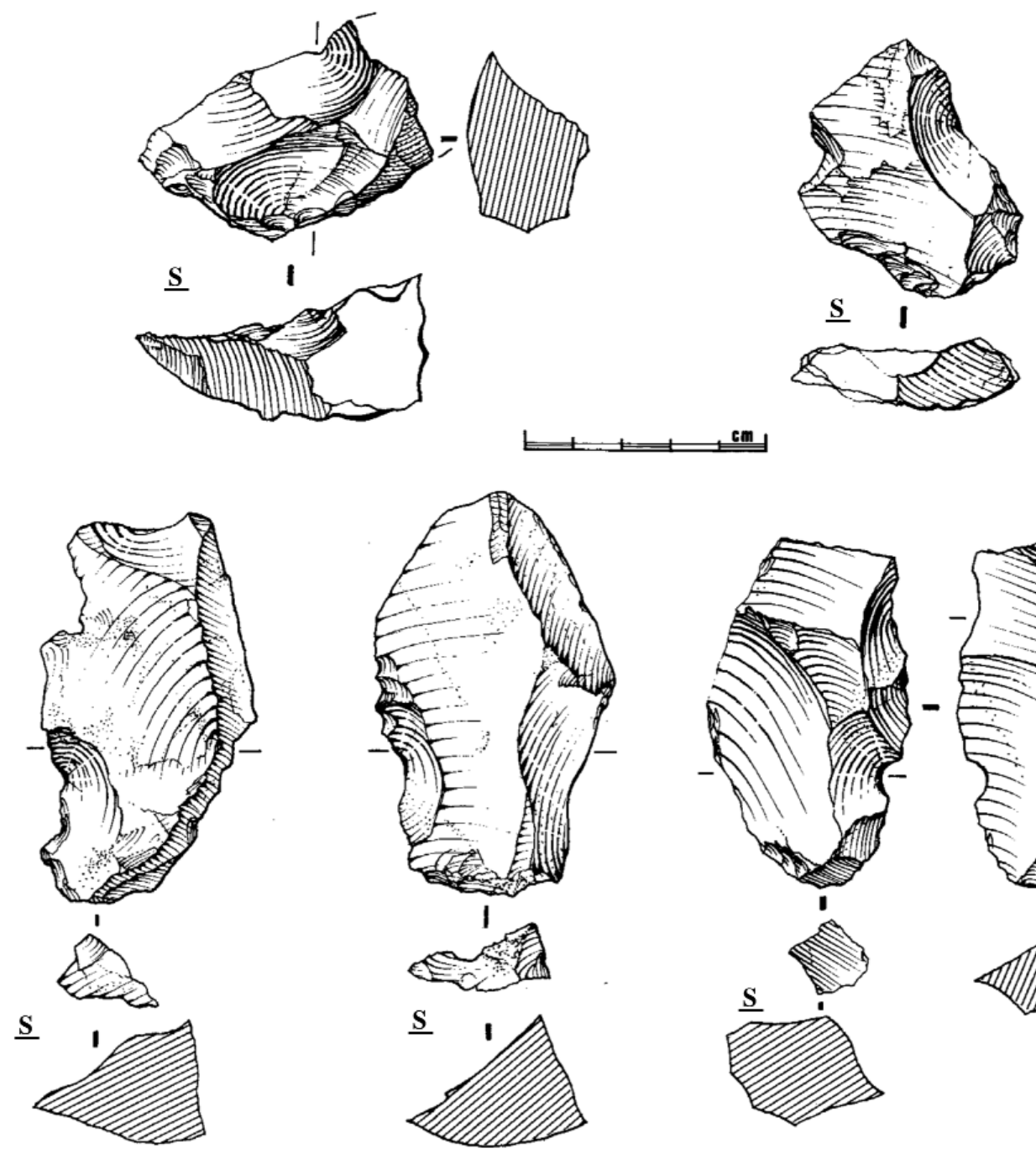

$\underline{\text { SA }}$

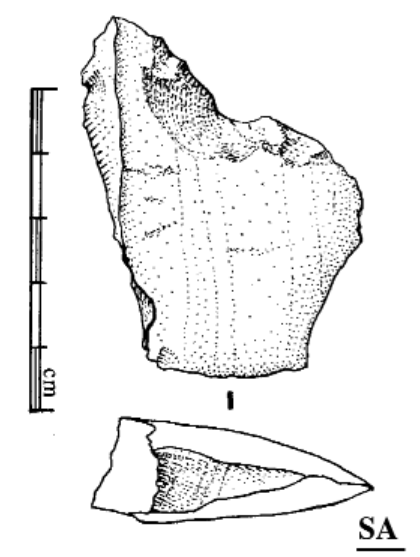

Figure 6 - Encoches : 1, encoche retouchée en silex ; 2, encoche clactonienne en schiste à andalousite ; 3, encoches clactoniennes en silex ; d'après Farizy et al. 1994).

Figure 6 - Notches : 1, flint retouched notch ; 2, schist clactonian notch ; 3, flint clactonian notches (Farizy et al. 1994). 

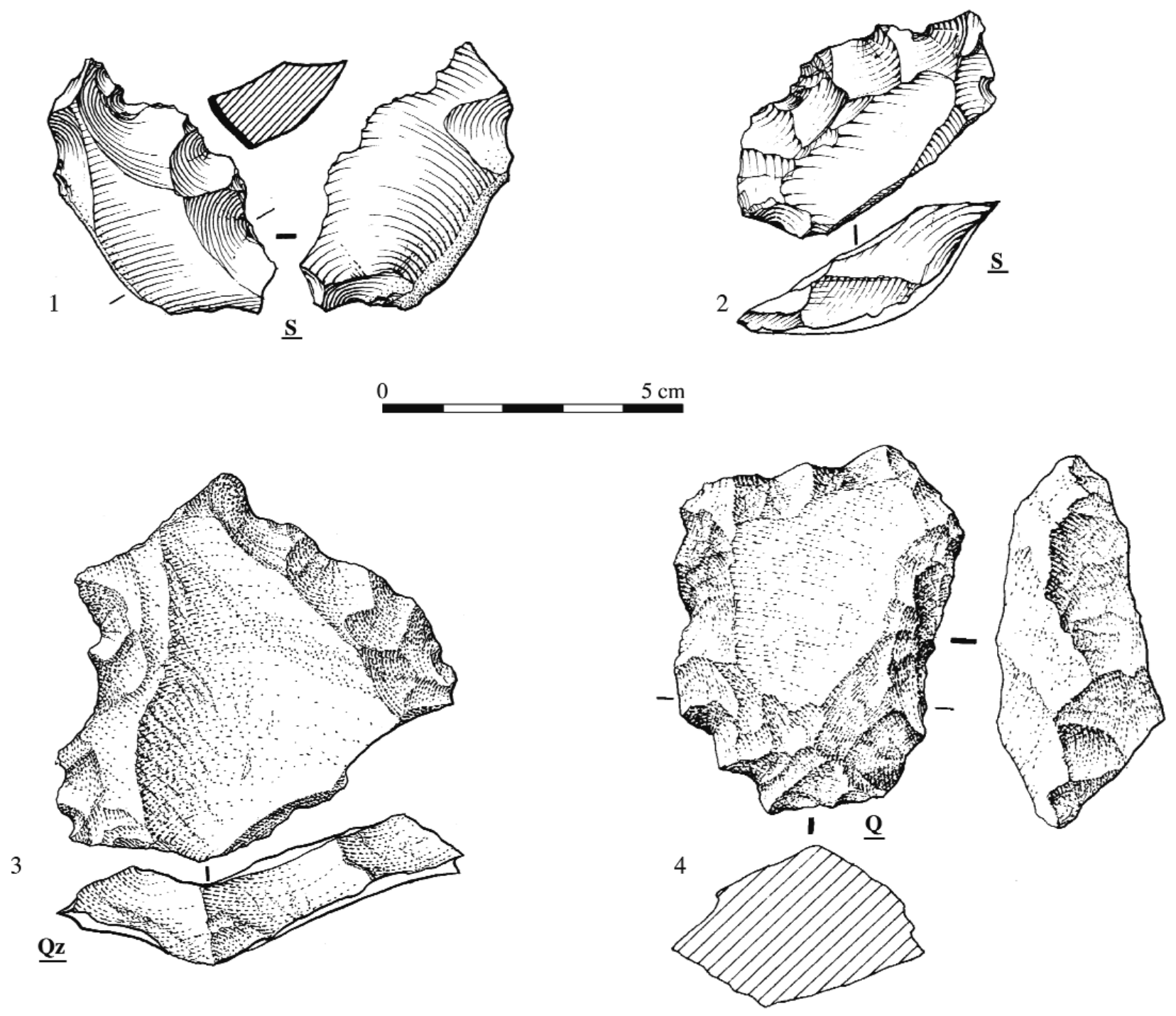

Figure 7 - Denticulés à macrodenticulation : 1 et 2, silex ; 3, quartzite ; 4, quartz (Farizy et al. 1994).

Figure 7 - Macrodenticulation denticulates : 1 et 2, flint ; 3, quartzite ; 4, quartz (Farizy et al. 1994).

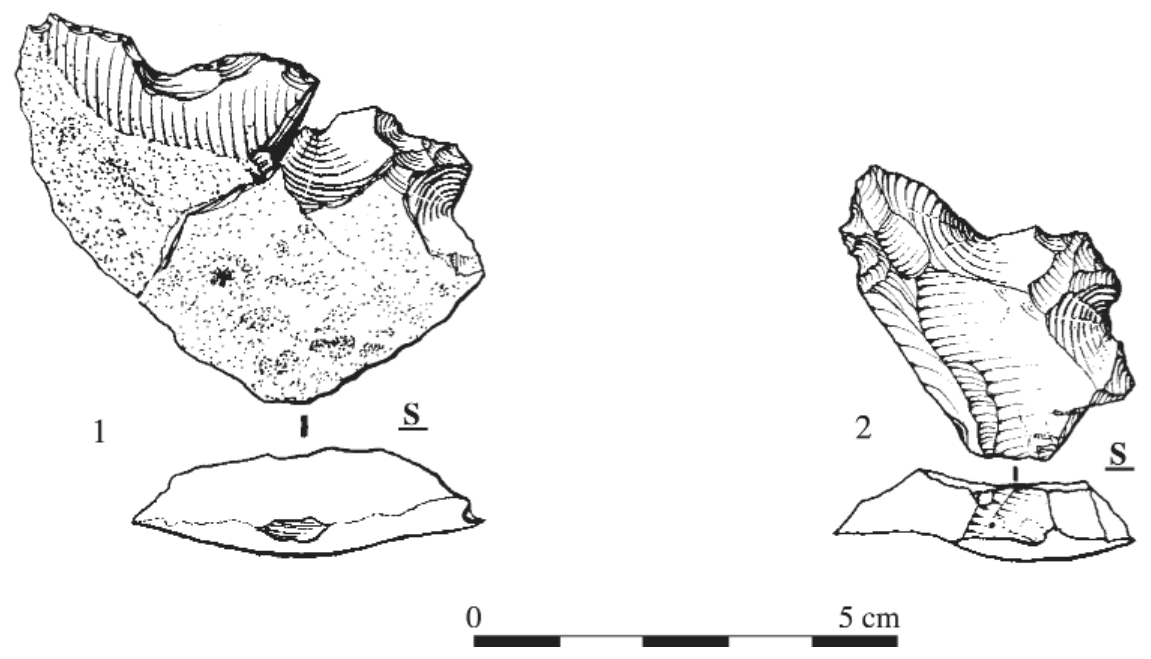

Figure 8 - Denticulés à macrodenticulation en silex dégageant un saillant (Farizy et al. 1994).

Figure 8 - Flint macrodenticulation denticulate showing a beak (Farizy et al. 1994). 

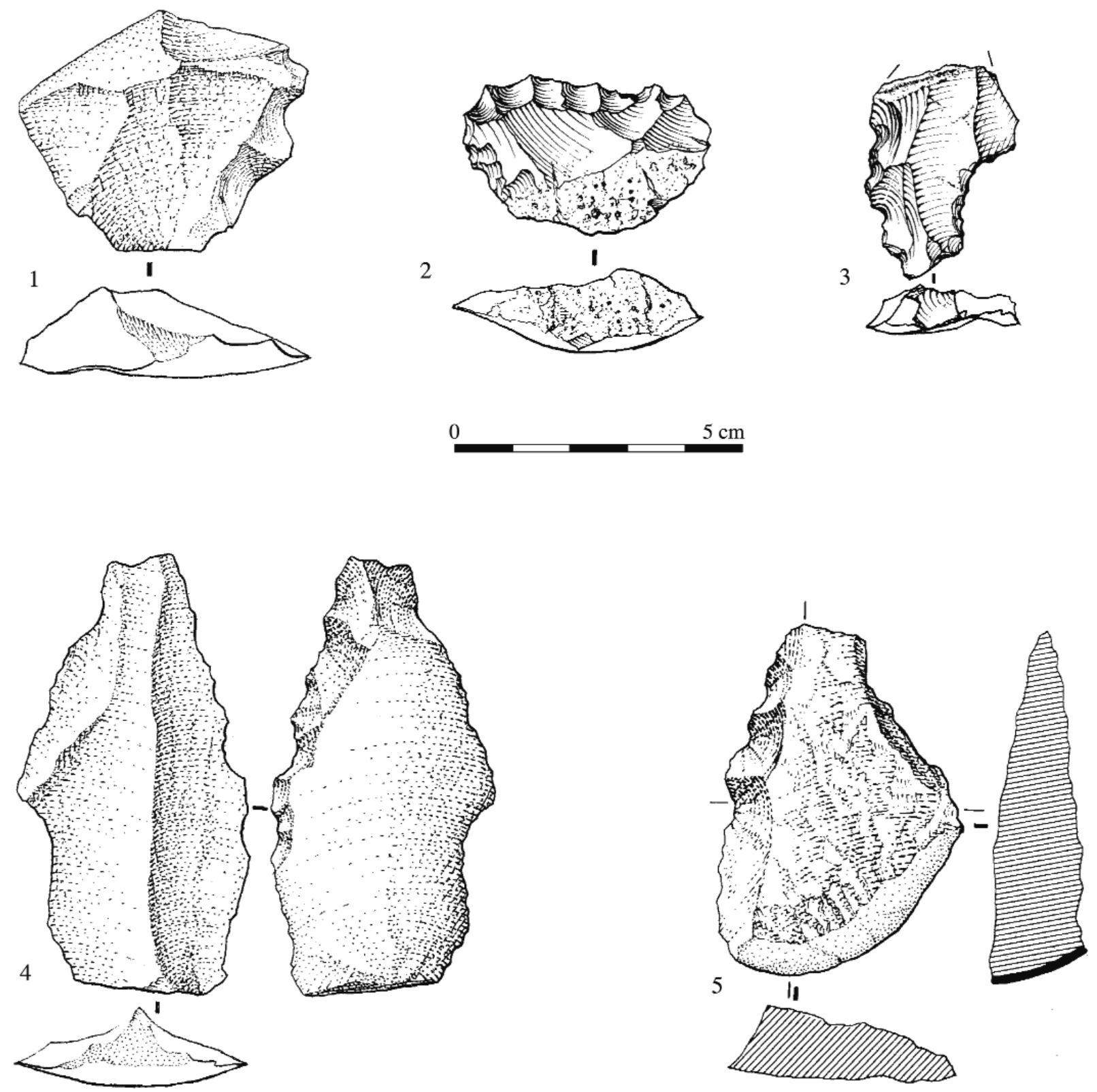

Figure 9 - Denticulés à moyenne denticulation : 1 et 4, quartzite ; 2 et 3, silex et 5, quartz (Farizy et al. 1994).

Figure 9 - Middle size denticulation denticulate : 1 et 4, quartzite ; 2 et 3, flint and 5, quartz (Farizy et al. 1994). 


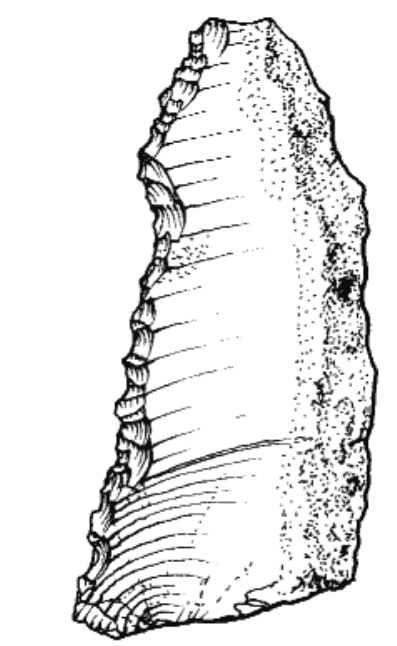

1

s I

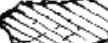

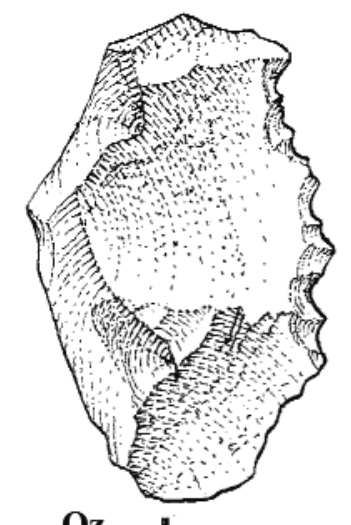

2

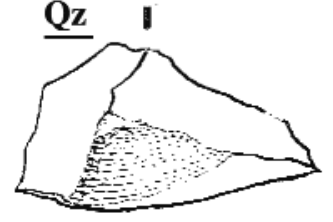

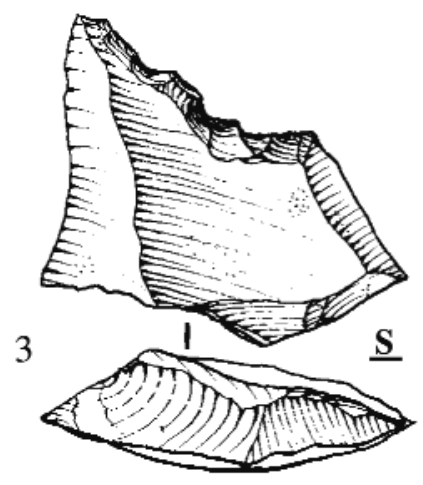

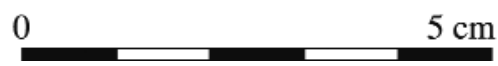

Figure 10 - Denticulés à microdenticulation : 1 et 3, silex et 2, quartzite (Farizy, David et Jaubert (Dir.) 1994).

Figure 10 - Microdenticulation denticulate : 1 et 3, flint and 2, quartzite (Farizy David et Jaubert (Dir.) 1994).

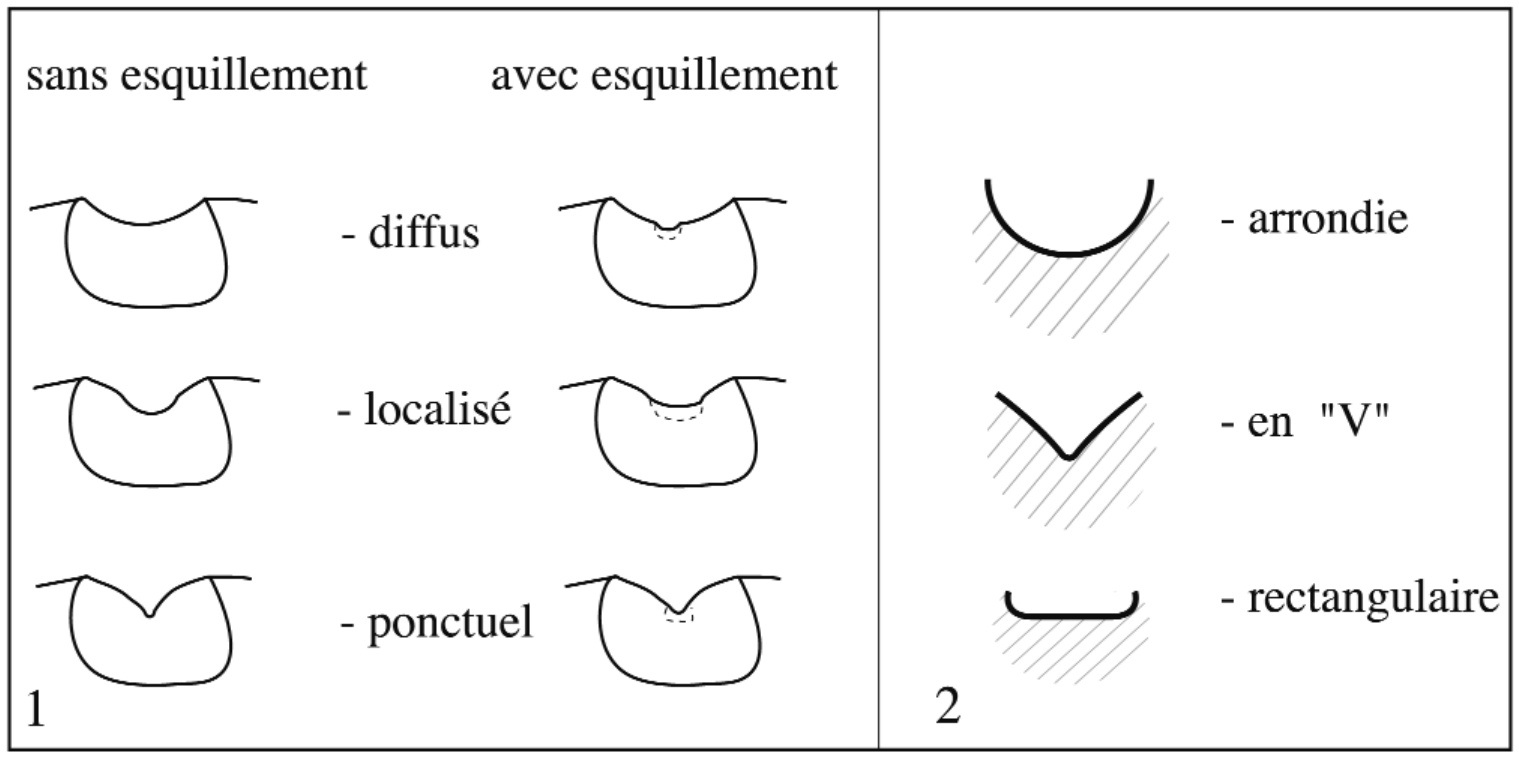

Figure 12 - 1, type de l'impact de l'encoche ; 2, morphologie de l'encoche.

Figure 12 - 1, notch impact type ; 2, notch morphology. 

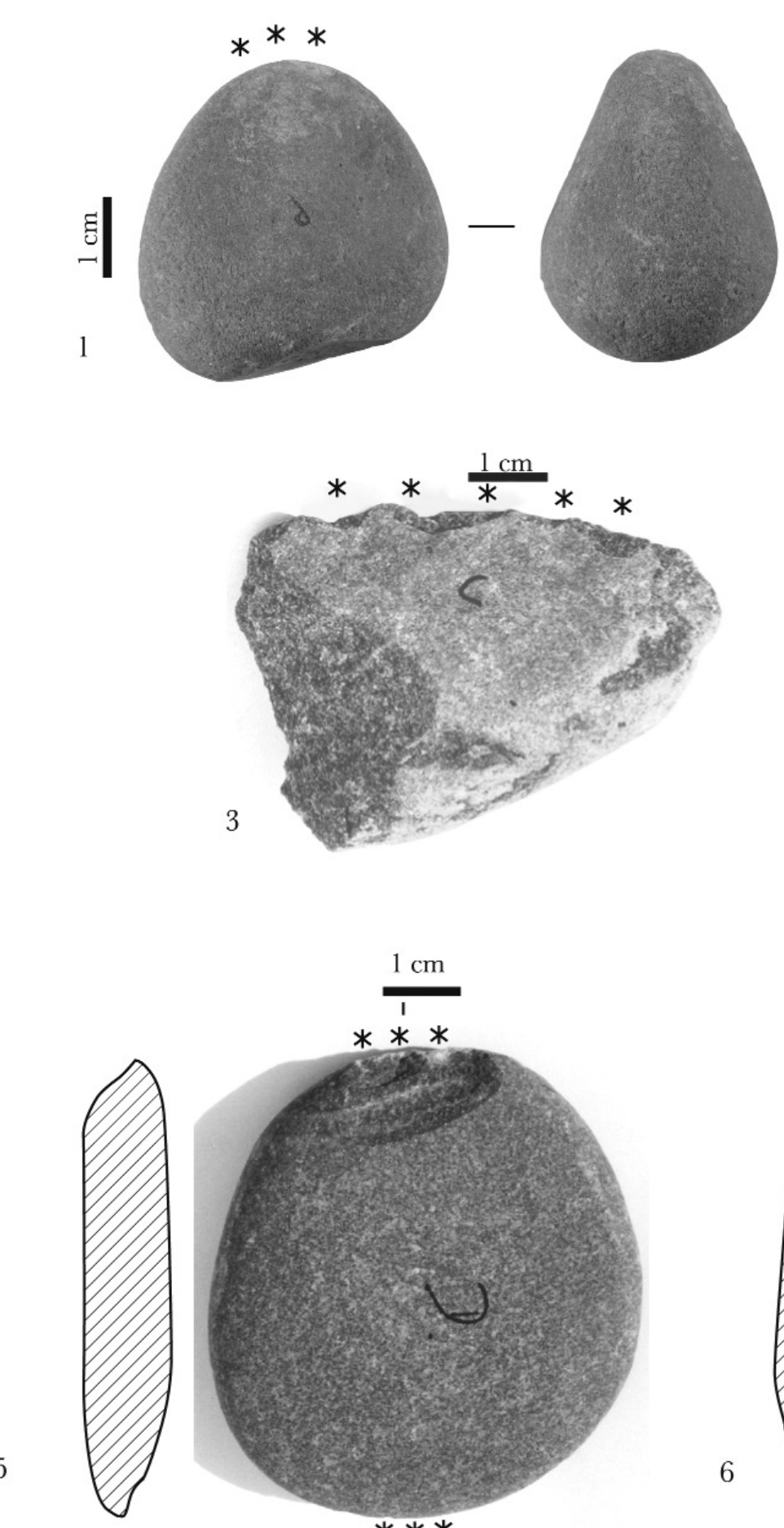

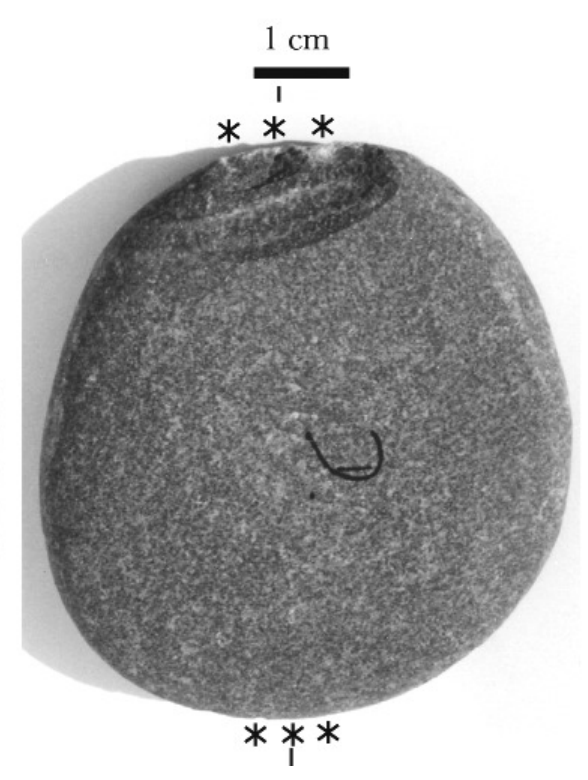

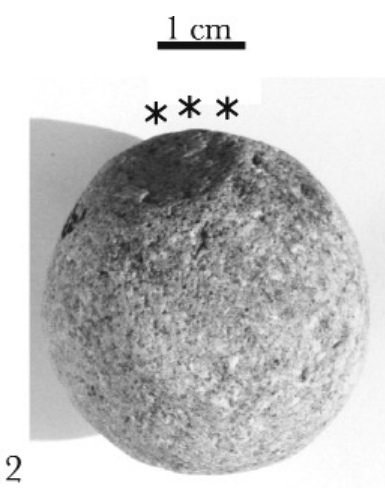

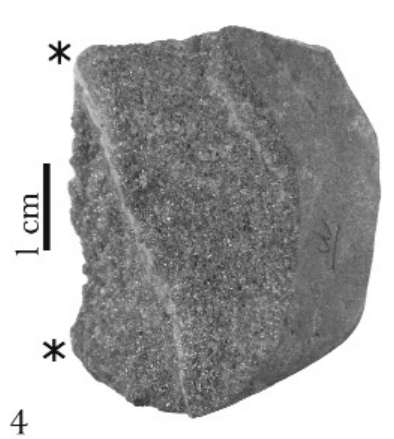

6

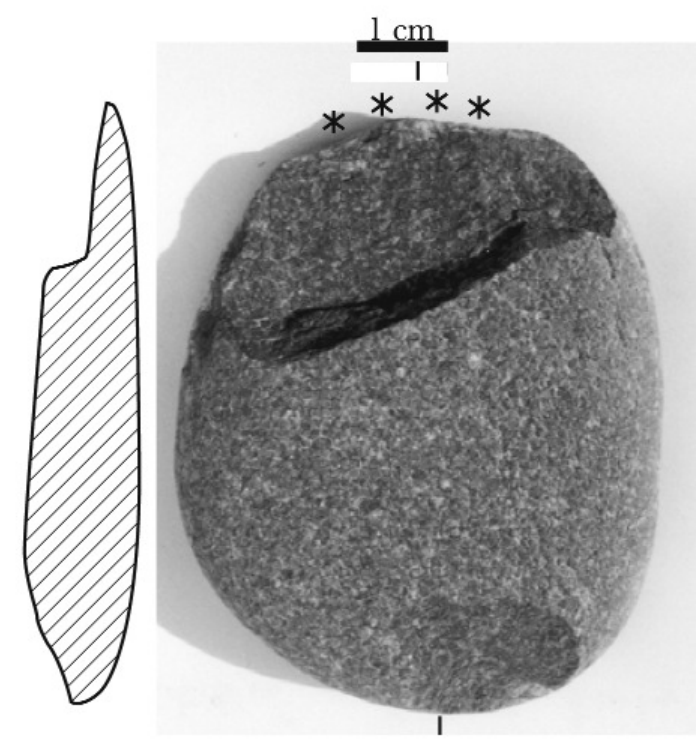

Figure 11 - Percuteurs expérimentaux : 1 et 2, galets à touche convexe (type 1); 3 et 4, tranchant d'éclats à touche dièdre (type 2) ; 5 et 6, galets plats percutés sur enclume à touches dièdres (type 3).

Figure 11 - Experimental hammerstones : 1 et 2, pebble with convex hammering surface (type 1); 3 et 4, flake edge with dihedral hammering surface (type 2) ; 5 et 6, flat pebbles splitted on anvil with dihedral hammering surfaces (type 3). 

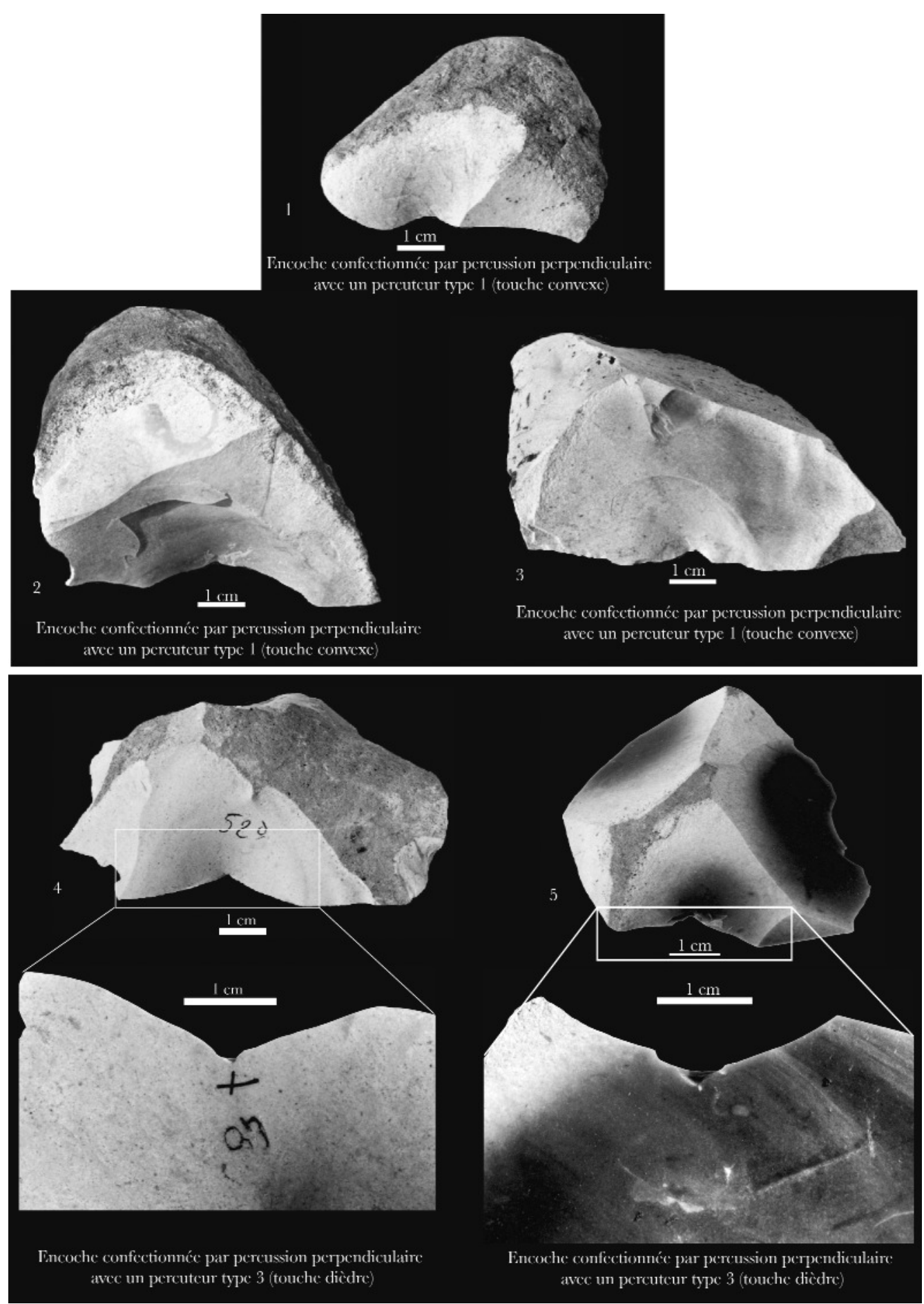

Figure 13 - Encoches clactoniennes expérimentales : 1, impact localisé ; 2 et 5, impact diffus avec esquillements ; 3 , impact localisé avec esquillements ; 4, impact ponctuel avec esquillements.

Figure 13 - Experimental clactonian notches : 1, localized impact ; 2 et 5, diffuse impact with splintering ; 3, localized impact with splintering ; 4, isolated impact with splintering. 


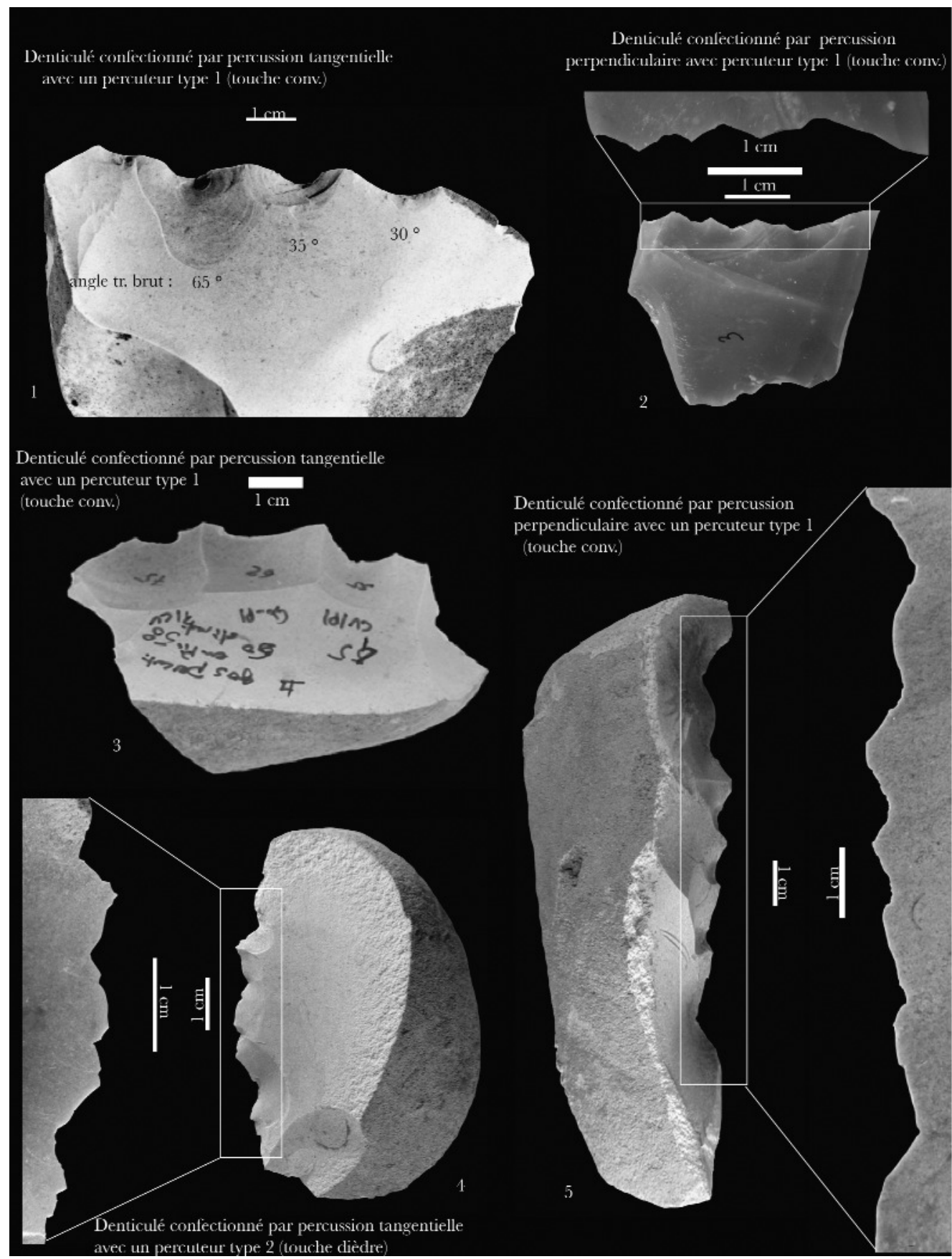

Figure 14 - Denticulés expérimentaux à macro et moyenne denticulation : 1, impacts diffus, à esquillements et localisés ; 2, impacts localisés avec esquillements et diffus avec esquillements ; 3, impacts localisés et diffus ; 4, impacts diffus et ponctuels ; 5, impacts diffus et localisés avec esquillements.

Figure 14 - Macro and middle size denticulation experimental denticulates : 1, diffuse, with splintering and localized impacts ; 2, localized impacts with splintering and et diffuse impacts with splintering ; 3 , localized and diffuse impacts ; 4, diffuse and isolated impacts ; 5, diffuse and isolated impacts with splintering. 


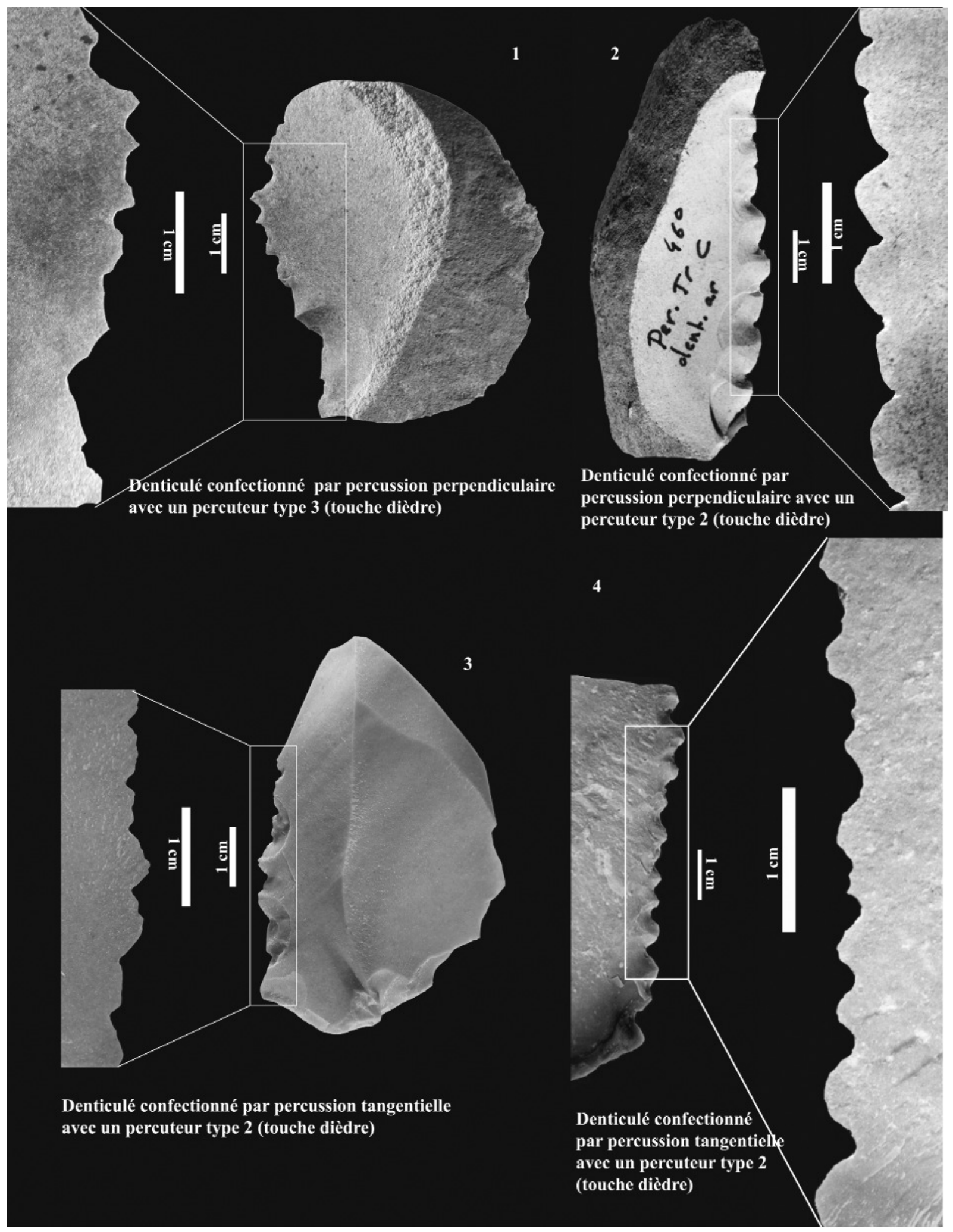

Figure 15 - Denticulés expérimentaux à microdenticulation : 1, impacts diffus et localisés avec esquillements ; 2, impacts ponctuels ; 3 , impacts localisés et ponctuels ; 4, impacts localisés avec esquillements.

Figure 15 - Microdenticulation experimental denticulates : 1, diffuse and localized impacts with splintering; 2, isolated impacts ; 3, localized and isolated impacts ; 4, localized impacts with splintering. 


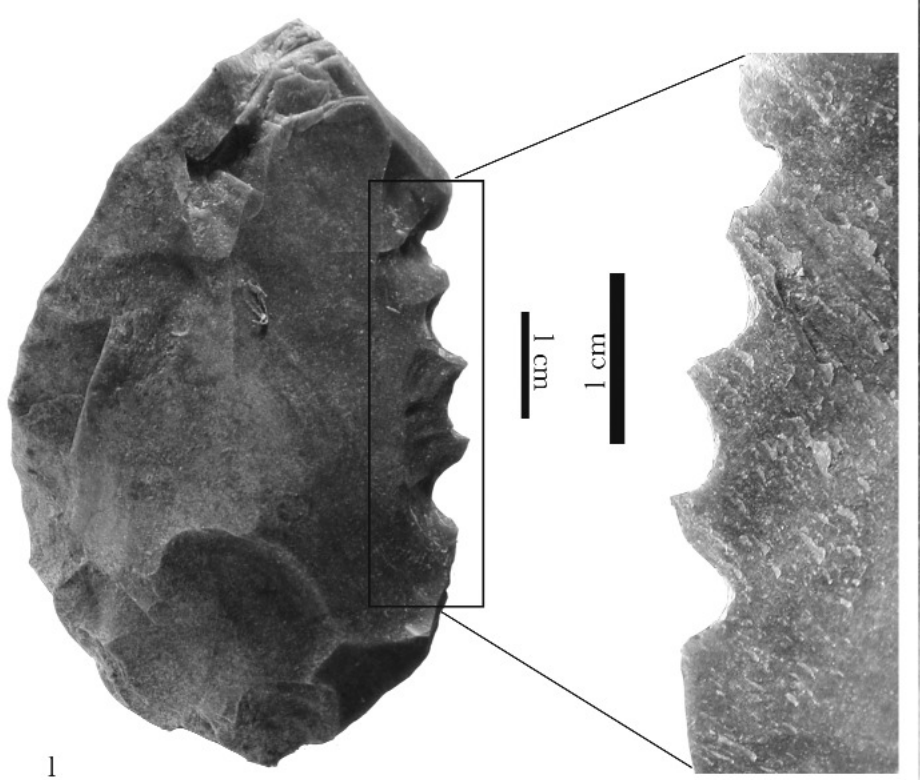

Denticulé confectionné par percussion tangentielle avec un percuteur type 1 (touche convexe)

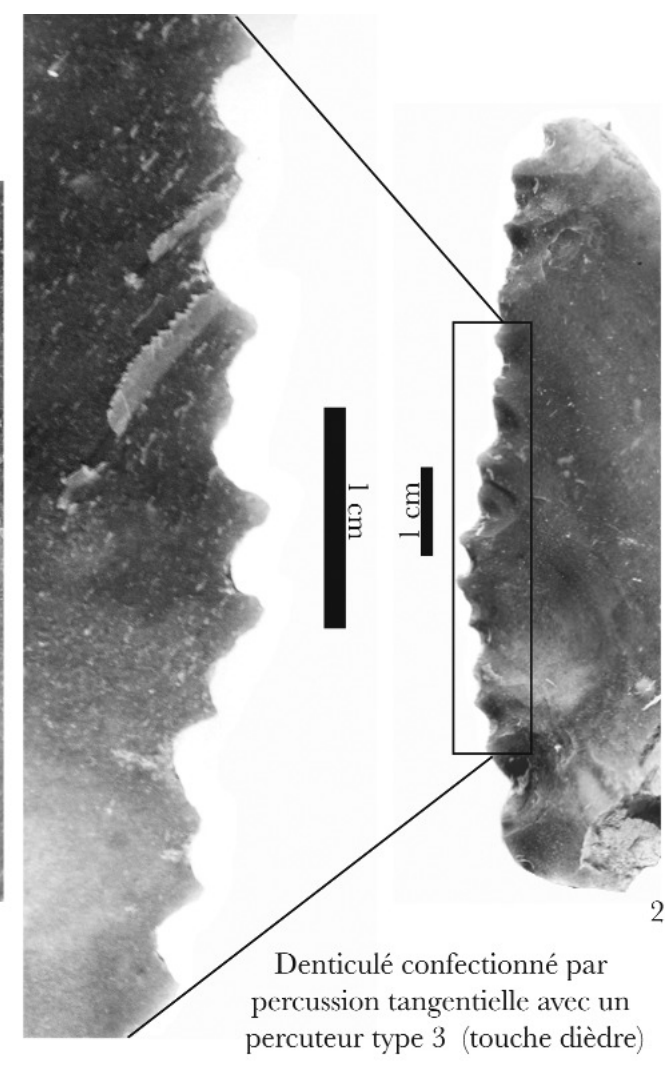

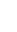




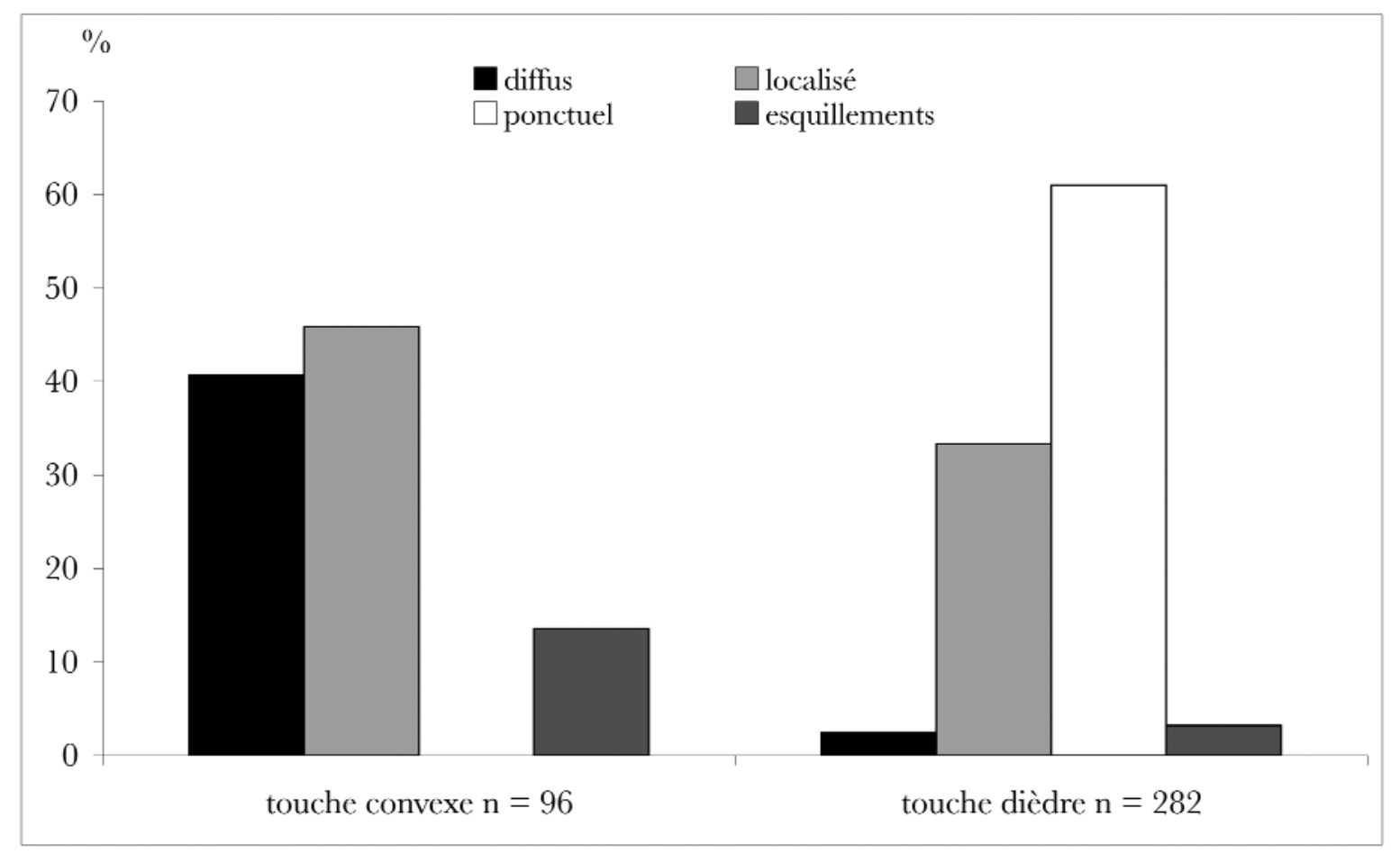

Figure 17 - Type de l'impact selon la touche du percuteur utilisé.

Figure 17 - Type of impact according to hammering surfaces of used hammerstones.

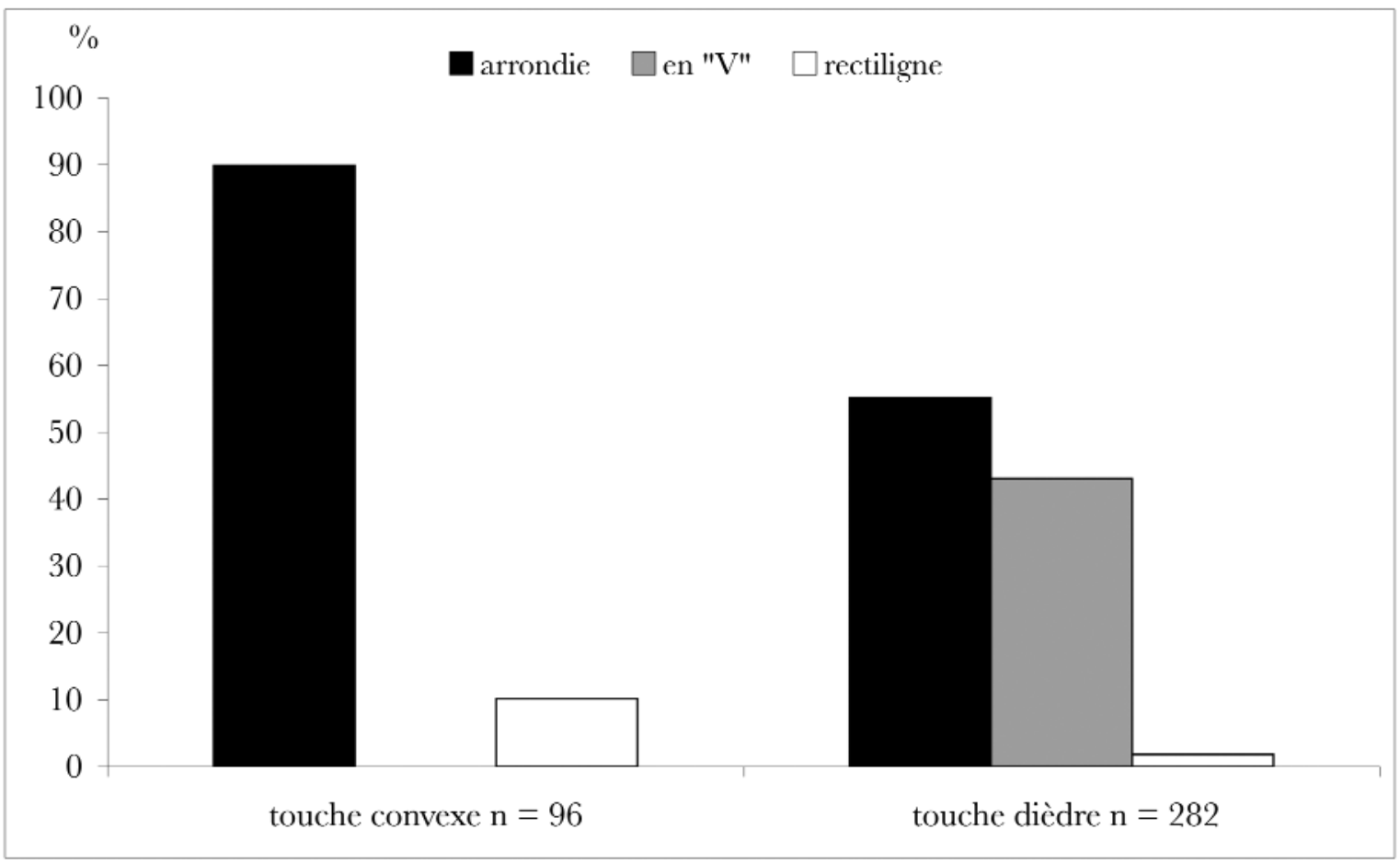

Figure 18 - Morphologie de l'encoche selon la touche du percuteur utilisé.

Figure 18 - Notch morphology according to hammering surfaces of used hammerstones. 


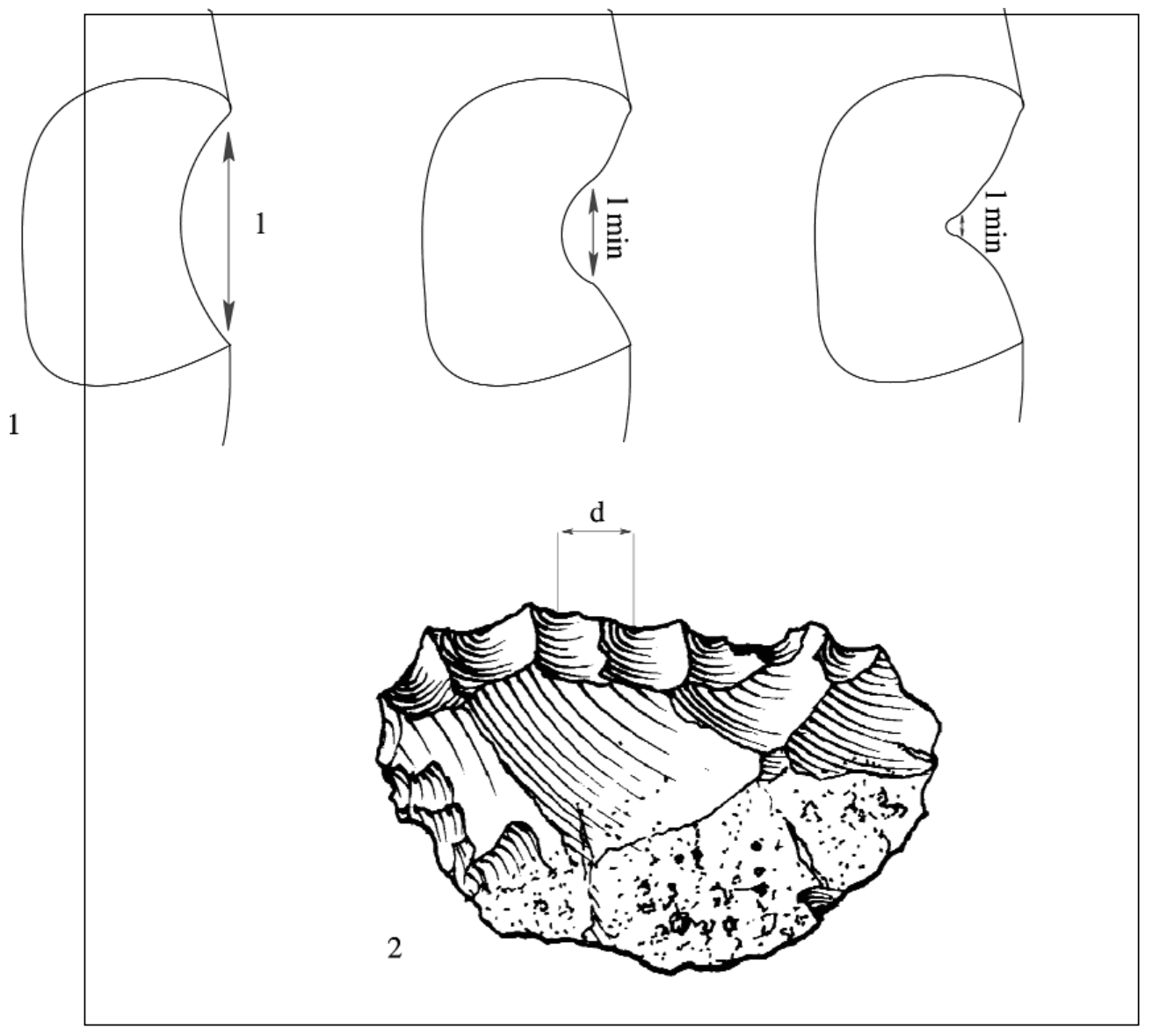

Figure 19 - 1, ouverture minimale de l'encoche selon le type d'impact; 2, distance entre les coches des denticulés.

Figure $19-1$, minimal opening of the notch according to impact type ; 2, distance between notches of denticulates.

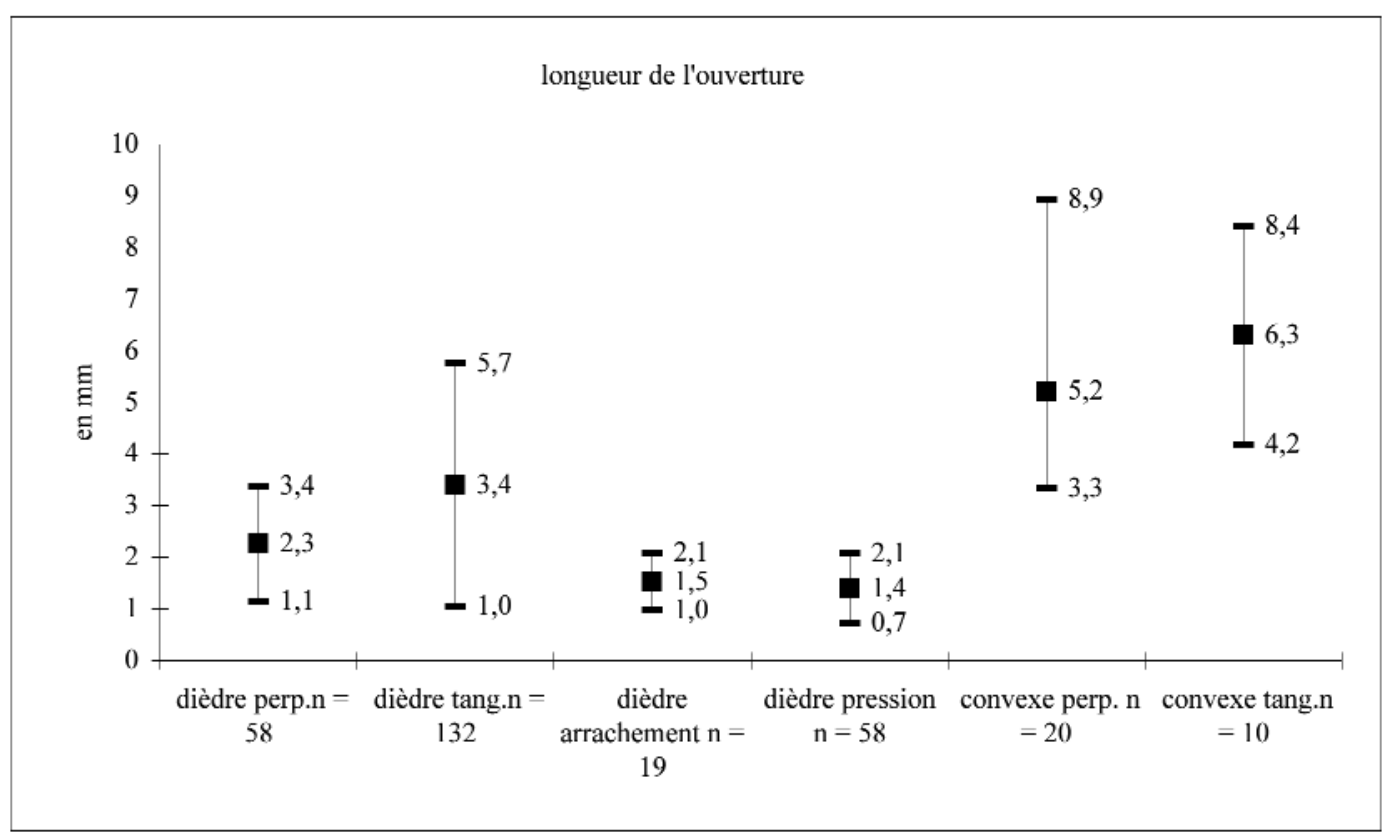

Figure 20 - Longueur moyenne et écart-type des ouvertures des coches des denticulés à microdenticulation selon la touche du percuteur utilisé.

Figure 20 - Mean length and standard deviation of the opening of the notches of microdenticulation denticulates according to hammering surfaces of used hammerstones. 


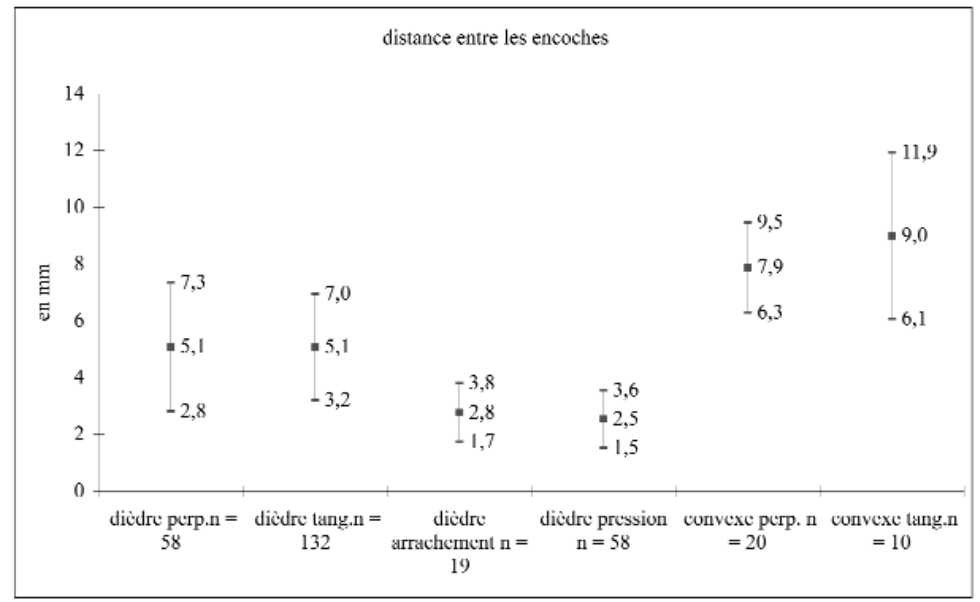

Figure 21- Longueur

moyenne et écart-type des distances entre les coches des denticulés à microdenticulation selon la touche du percuteur utilisé.

Figure 21 - Mean length and standard deviation of the distance between notches of microdenticulation denticulates according to hammering surfaces of used hammerstones.

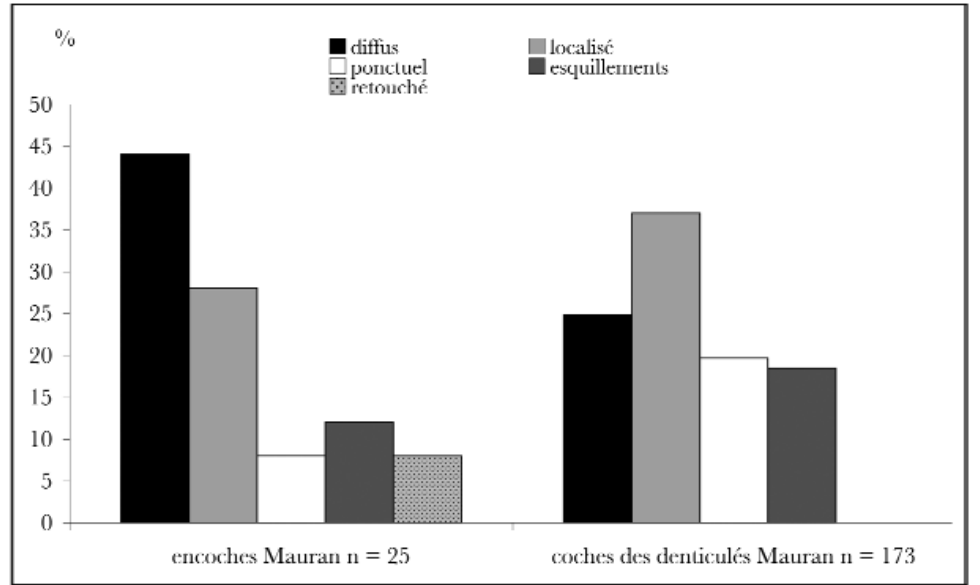

Figure 22 - Types d'impact des encoches et des coches des denticulés de Mauran.

Figure 22 - Impact types of Mauran notches and denticulates' notches.

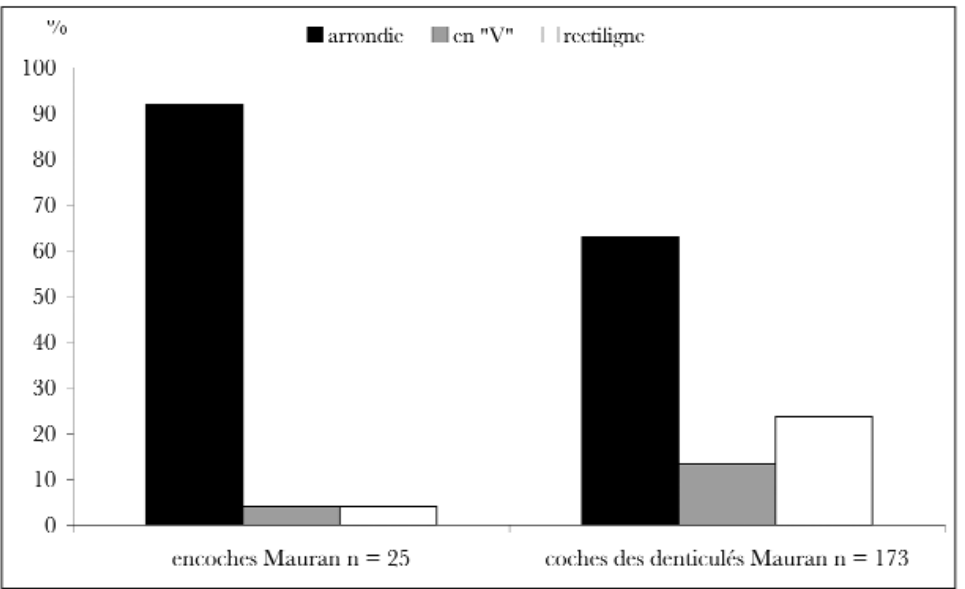

Figure 23 - Morphologie des encoches et des coches des denticulés de Mauran.

Figure 23 - Morphology of Mauran notches and denticulates' notches.

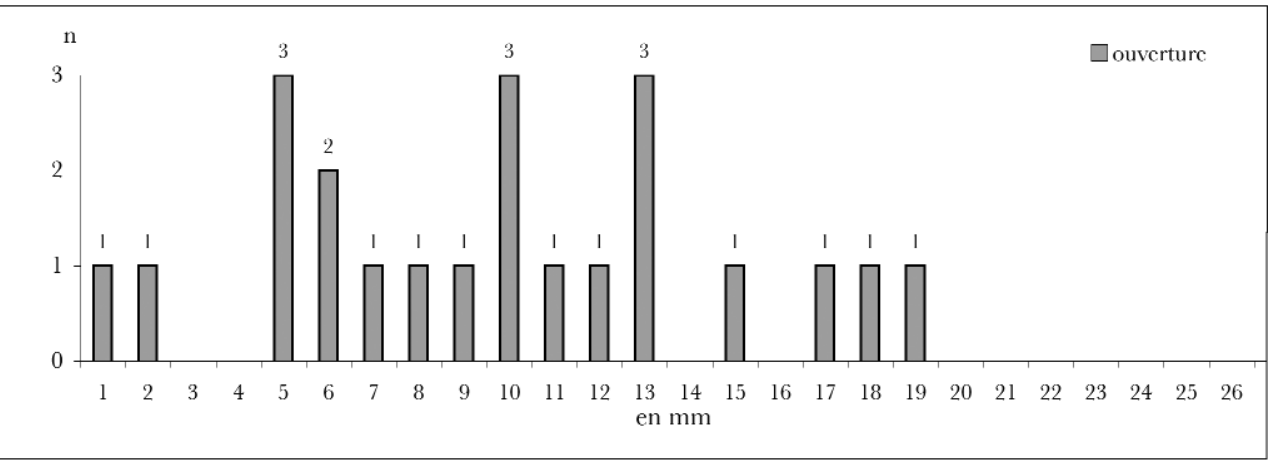

Figure 24 - Longueurs d'ouverture des encoches de Mauran.

Figure 24 - Opening lengths of Mauran notches. 

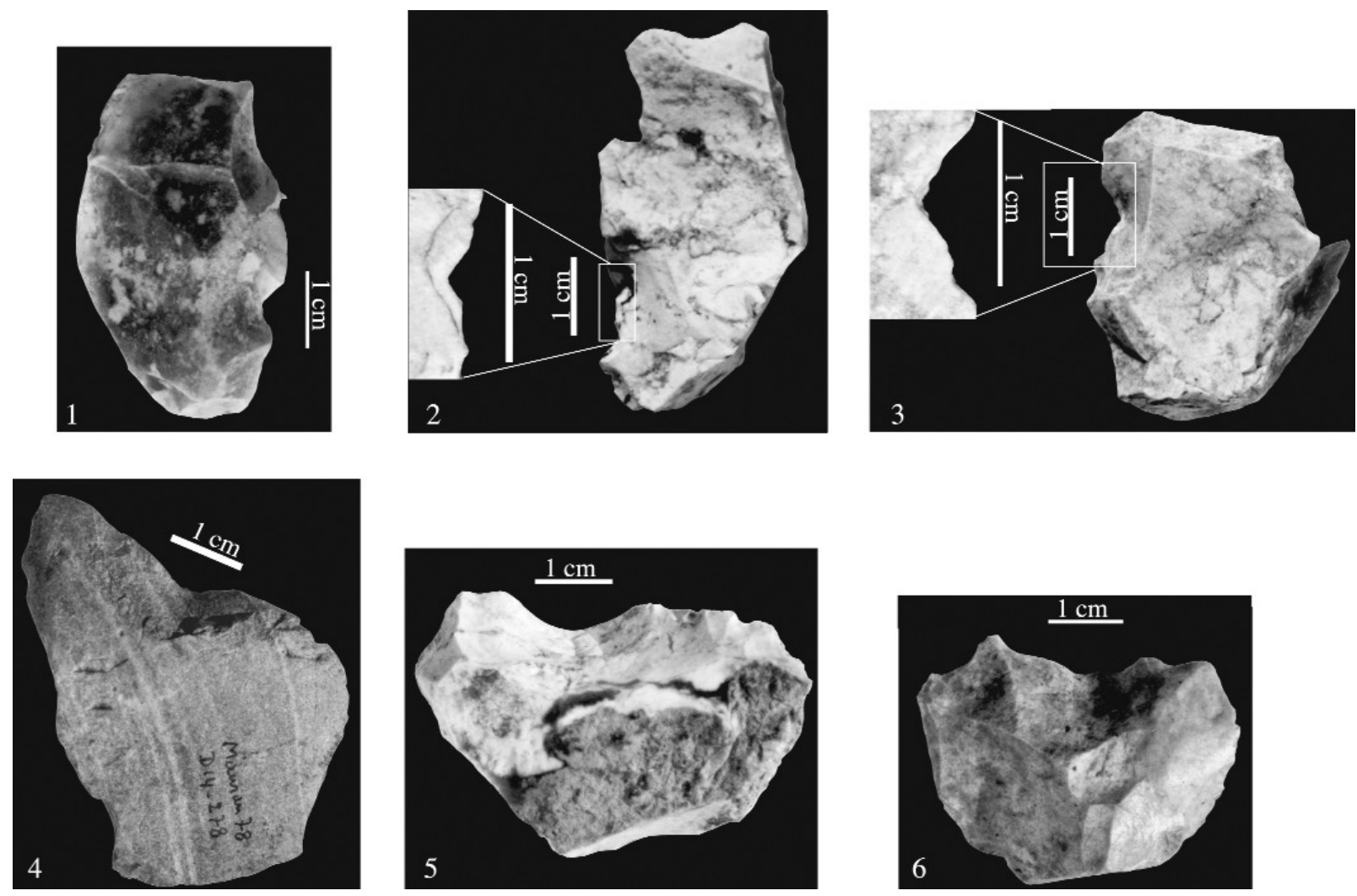

Figure 25 - Encoches clactoniennes de Mauran : 1, 2, 3, 5 et 6 silex ; 4 schiste à andalousite ; 1 et 4, impact localisé ; 2 et 3 , impact ponctuel ; 5 et 6 , impact diffus.

Figure 25 - Mauran clactonian notches : 1, 2, 3, 5 and 6 flint ; 4 andalousite schist ; 1 and 4, localized impact ; 2 and 3, isolated impact ; 5 and 6, diffuse impact. 


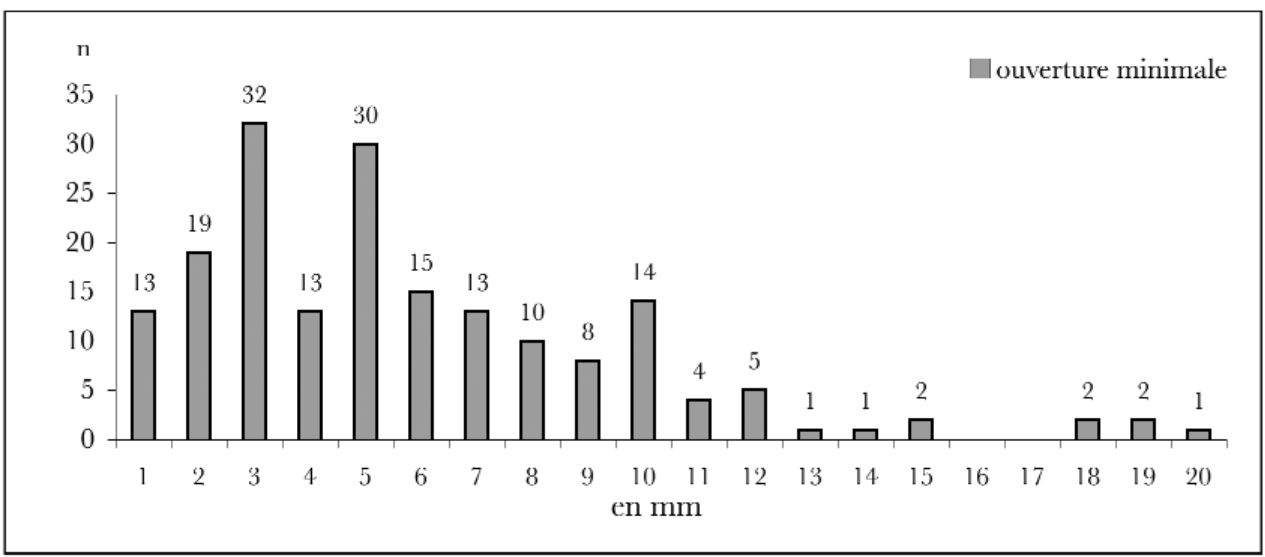

Figure 26 - ouverture

minimale des coches des denticulés de Mauran.

Figure 26 - minimal opening of the Mauran denticulates' notches.

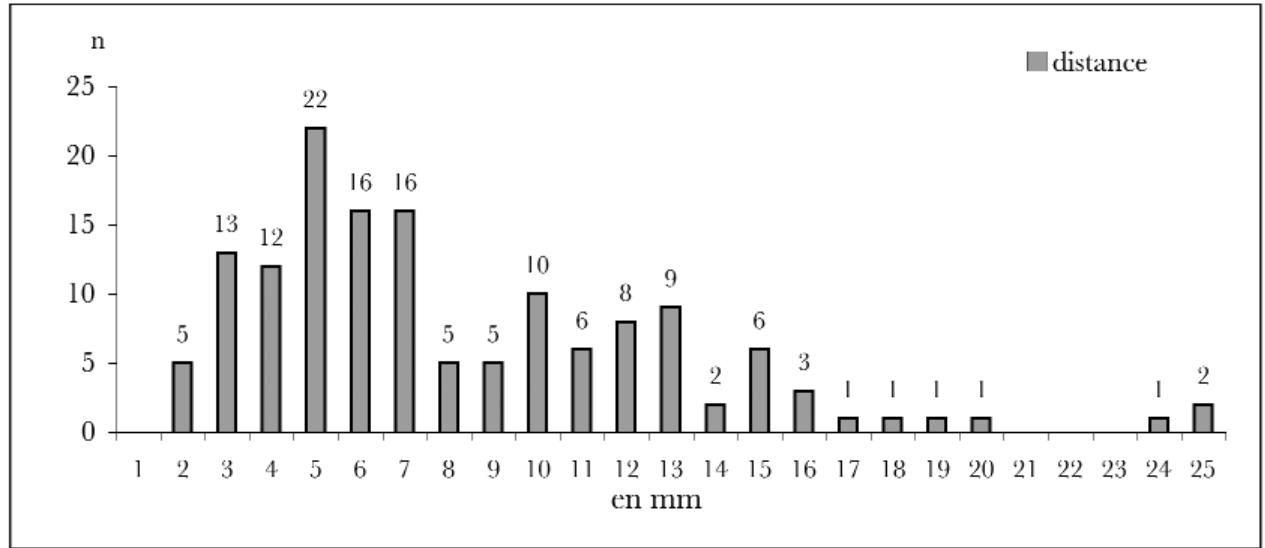

Figure 27 - Distances entre les coches des denticulés de Mauran

Figure 27 - Distance between the Mauran denticulates' notches.

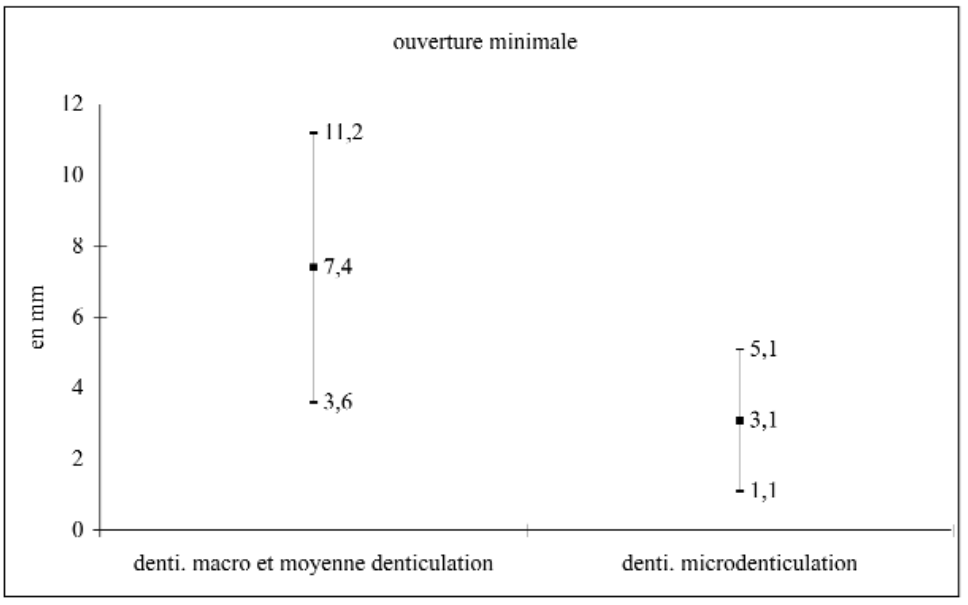

Figure 28 - Moyennes et écart-types des ouvertures des coches des denticulés de Mauran.

Figure 28 - Mean measure and standard deviation of the Mauran denticulates' notches openings.

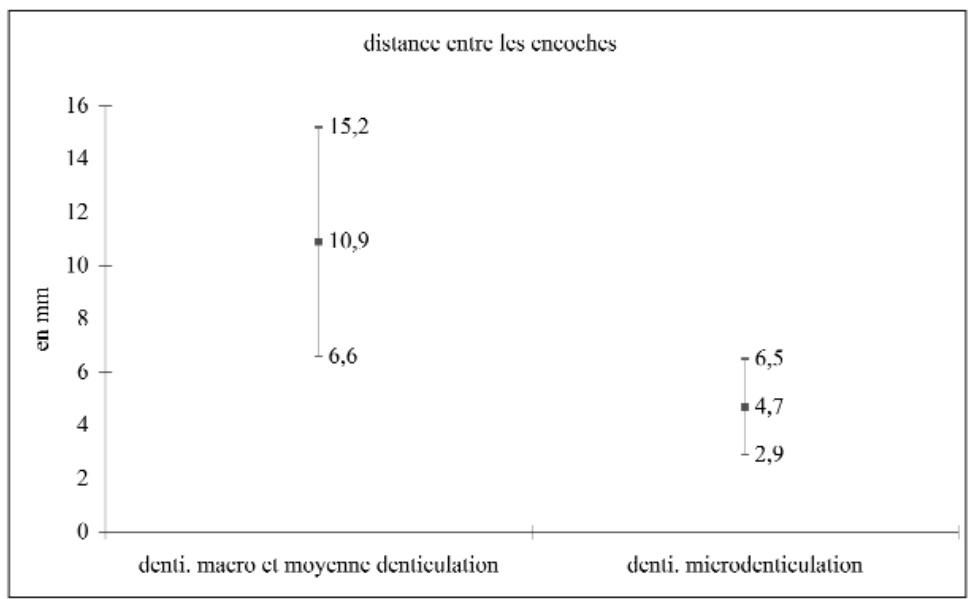

Figure 29 - Moyennes et écart-types des distances entre les coches des denticulés de Mauran.

Figure 29 - Mean distance and standard deviation between the Mauran denticulates' notches. 


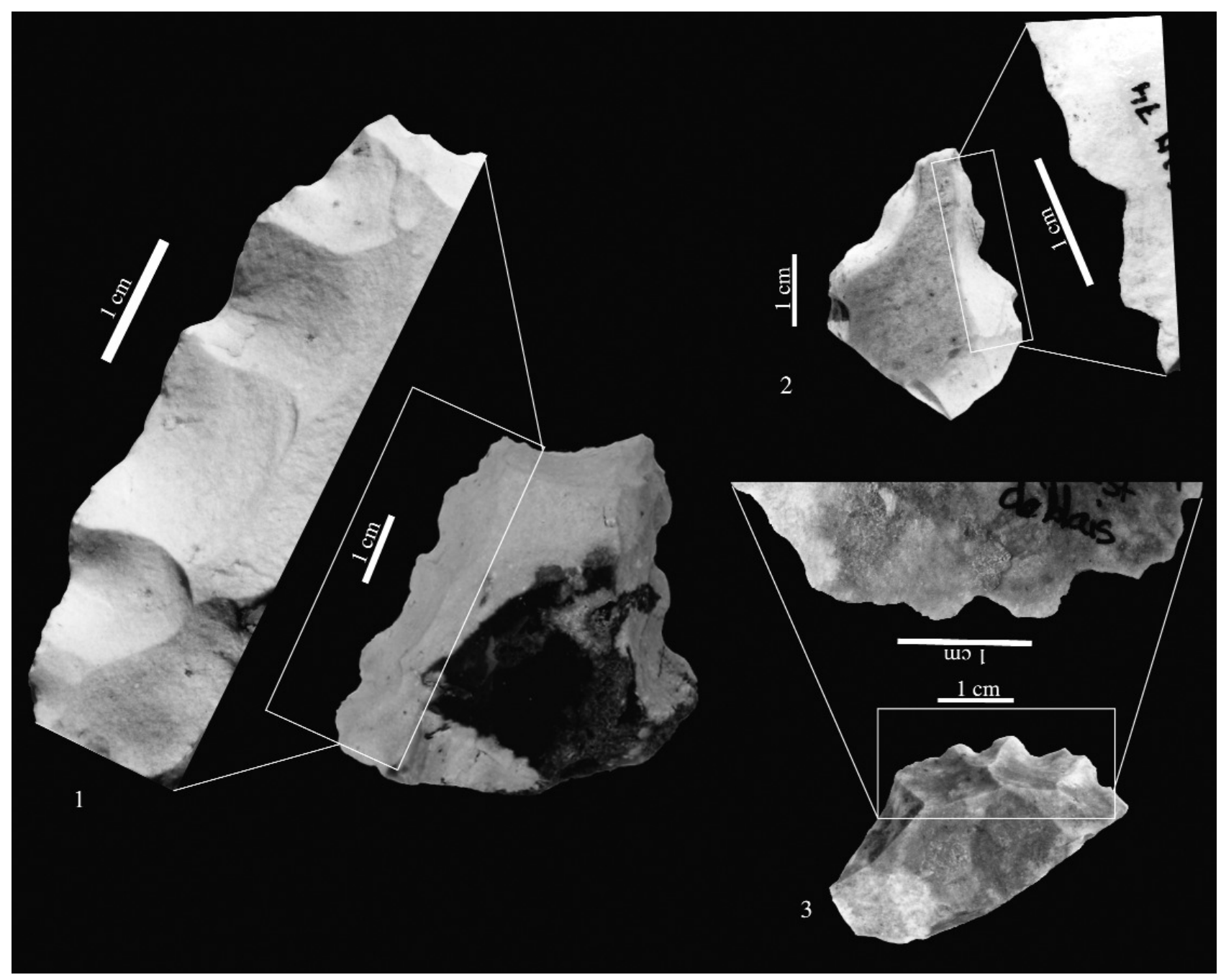

Figure 30 - Denticulés et fragment de pointe de Tayac en silex de Mauran : 1, impact localisé, diffus et localisé ; 2, impact localisé et ponctuel ; 3 , impacts diffus et localisés.

Figure 30 - Denticulates and flint Tayac point fragment from Mauran : 1, localized, diffuse and localized impact; 2, localized and isolated impact ; 3, diffuse and localized impacts. 

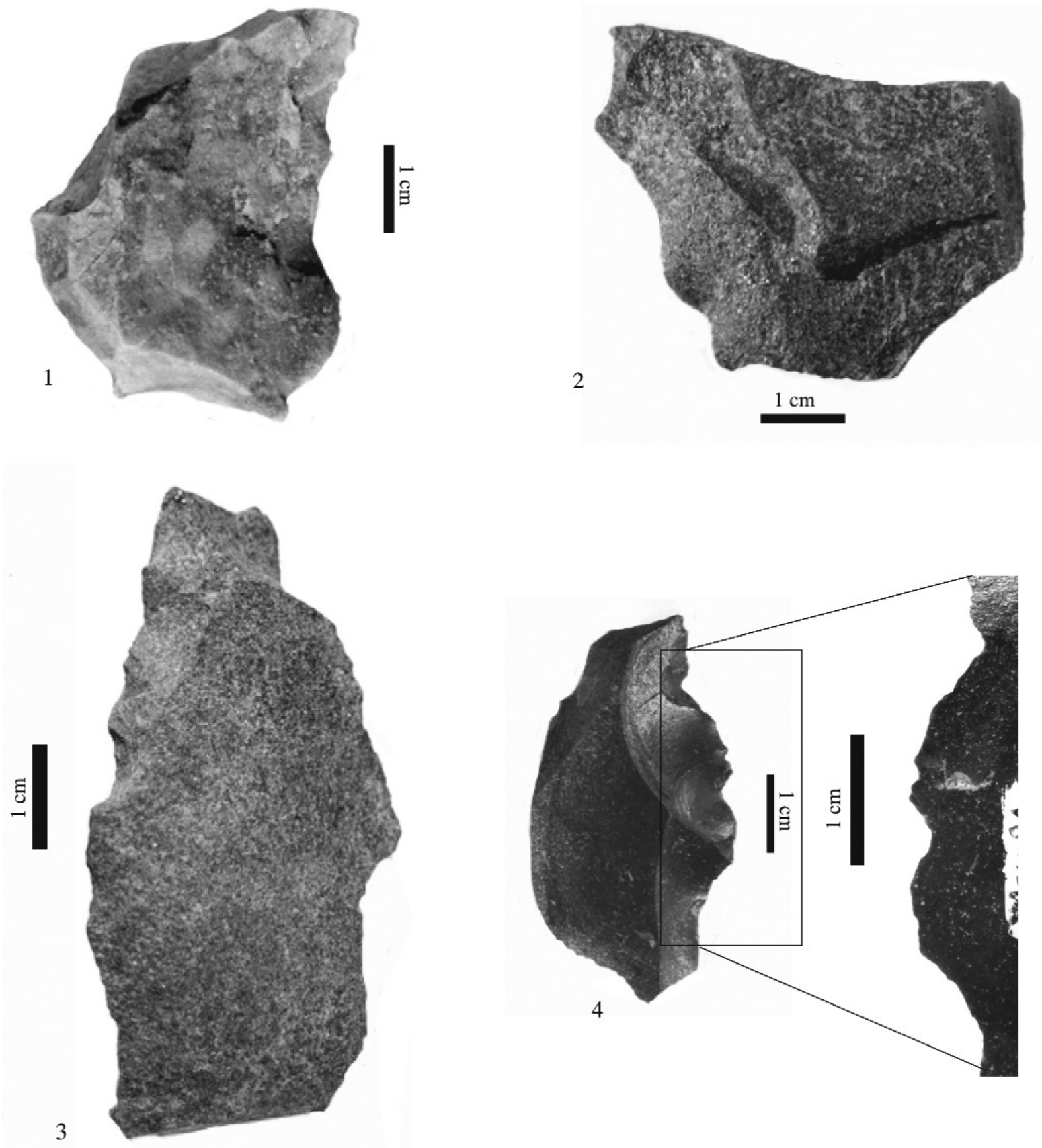

Figure 31 - Denticulés de Mauran : 1 à 3, quartzite et 4, silex ; 1, impacts diffus ; 2, impacts diffus et localisé, 3, impacts esquillés et diffus ; 4, impacts diffus, localisé et esquillé.

Figure 31 - Mauran denticulates : 1-3, quartzite, 4, flint ; 1, diffuse impacts ; 2, diffuse and localized impacts, 3, splintered and diffuse impacts ; 4, diffuse, localized and splintered impacts. 

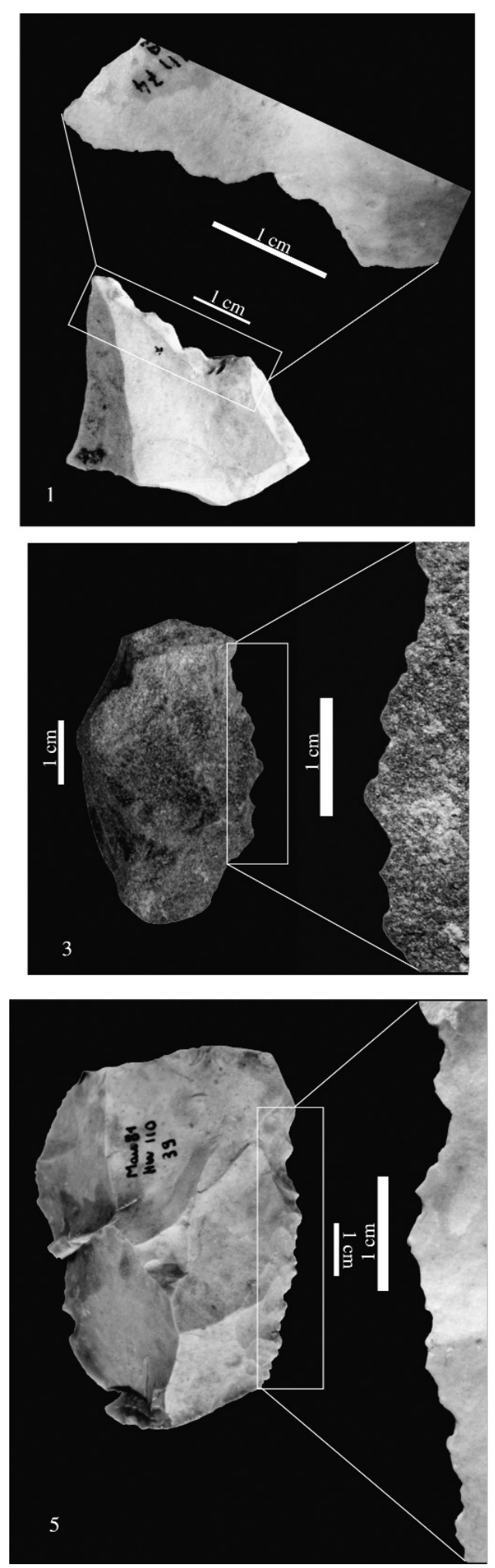
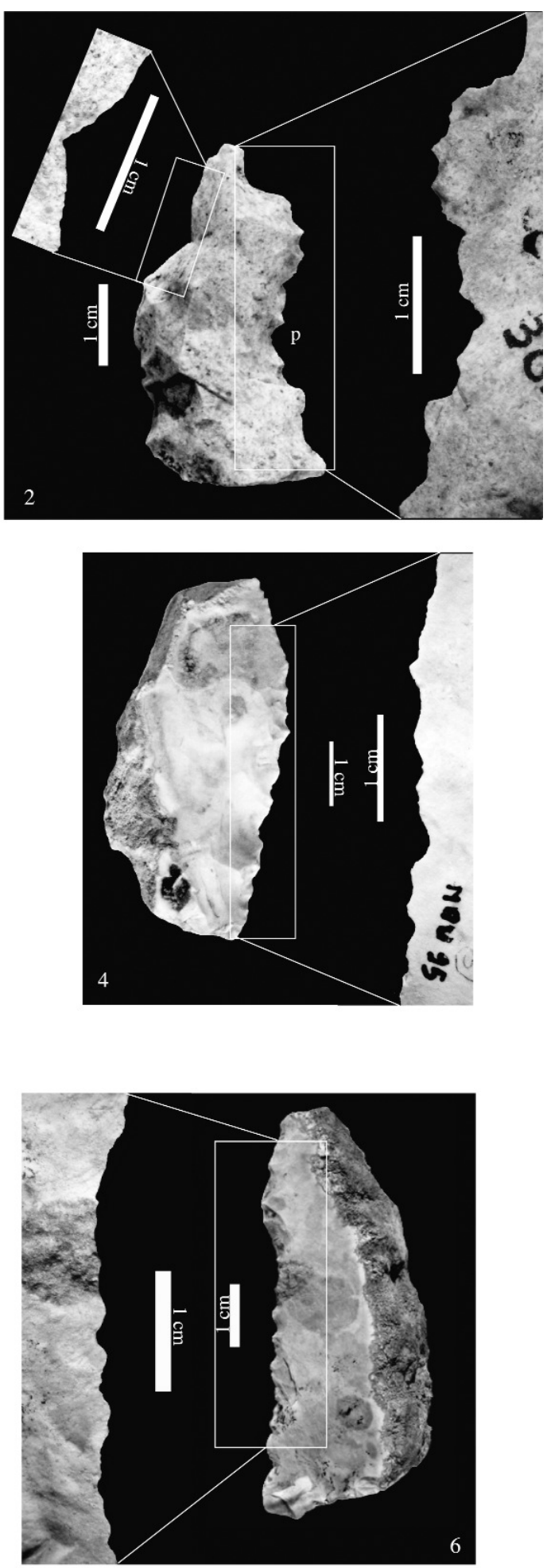

Figure 32 - Denticulés à microdenticulation de Mauran : 1, 2 et 4 à 6 silex et 3, quartzite. 1, impacts ponctuels, 2, impacts ponctuels et localisés ; 3 , impacts localisés, diffus et ponctuels ; 4, impacts localisés ; 5, impacts ponctuels et localisés, 6 , impacts ponctuels, localisés et esquillés.

Figure 32 - Mauran microdenticulation denticulates : 1, 2 and 4 - 6 flint and 3, quartzite. 1, isolated impacts, 2, isolated and localized impacts ; 3 , localized, diffuse and isolated impacts ; 4, localized impacts ; 5 , isolated and localized impacts, 6 , isolated, localized and splintered impacts. 

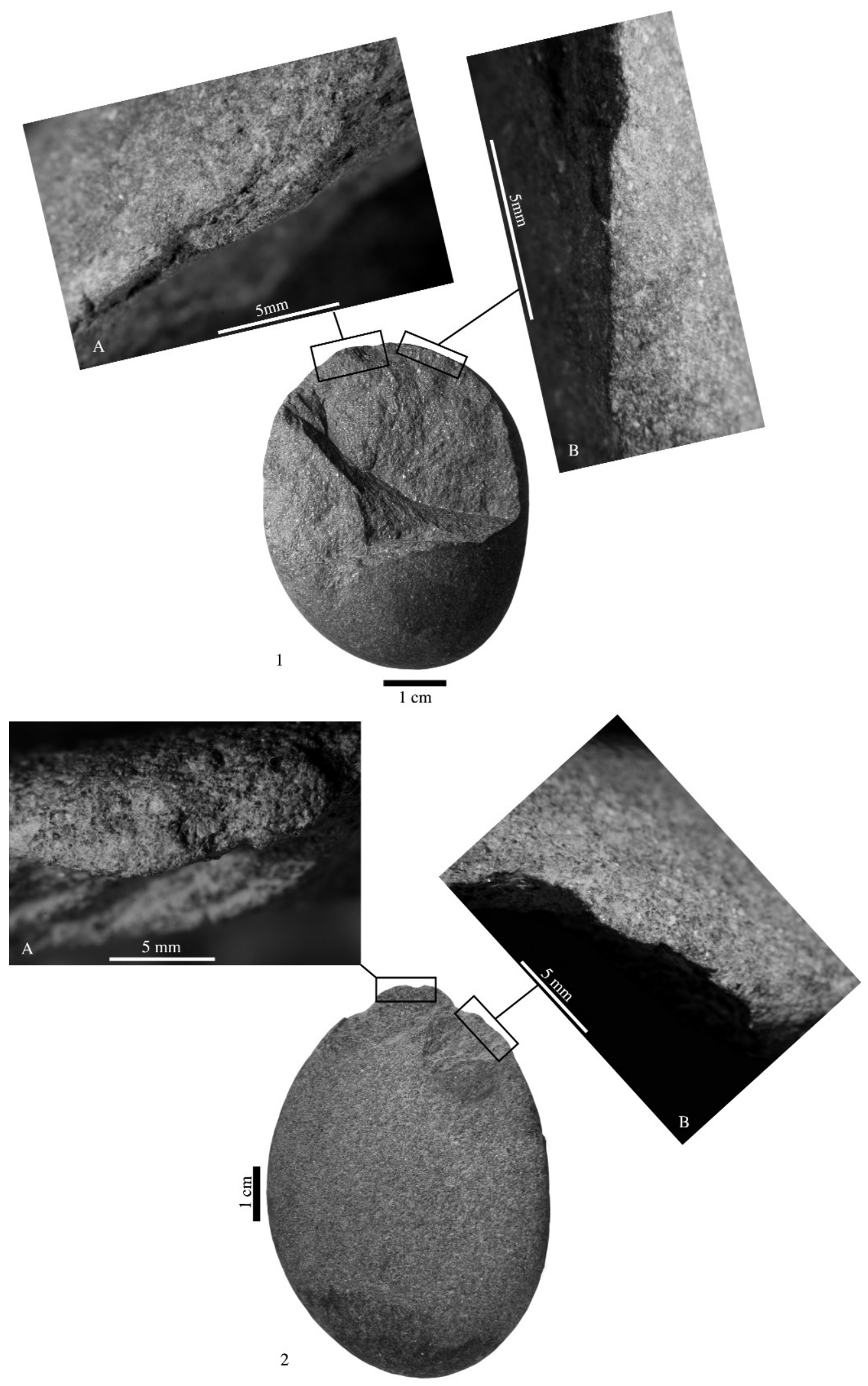

Figure 33 - Galets percutés de Mauran : 1A, zone utilisée, 1B, zone non utilisée ; $2 A$, zone utilisée, 2B, zone non utilisée.

Figure 33 - Mauran hammered pebbles : 1A used area, 1B, non used area ; $2 A$ used area, 2B, non used area. 

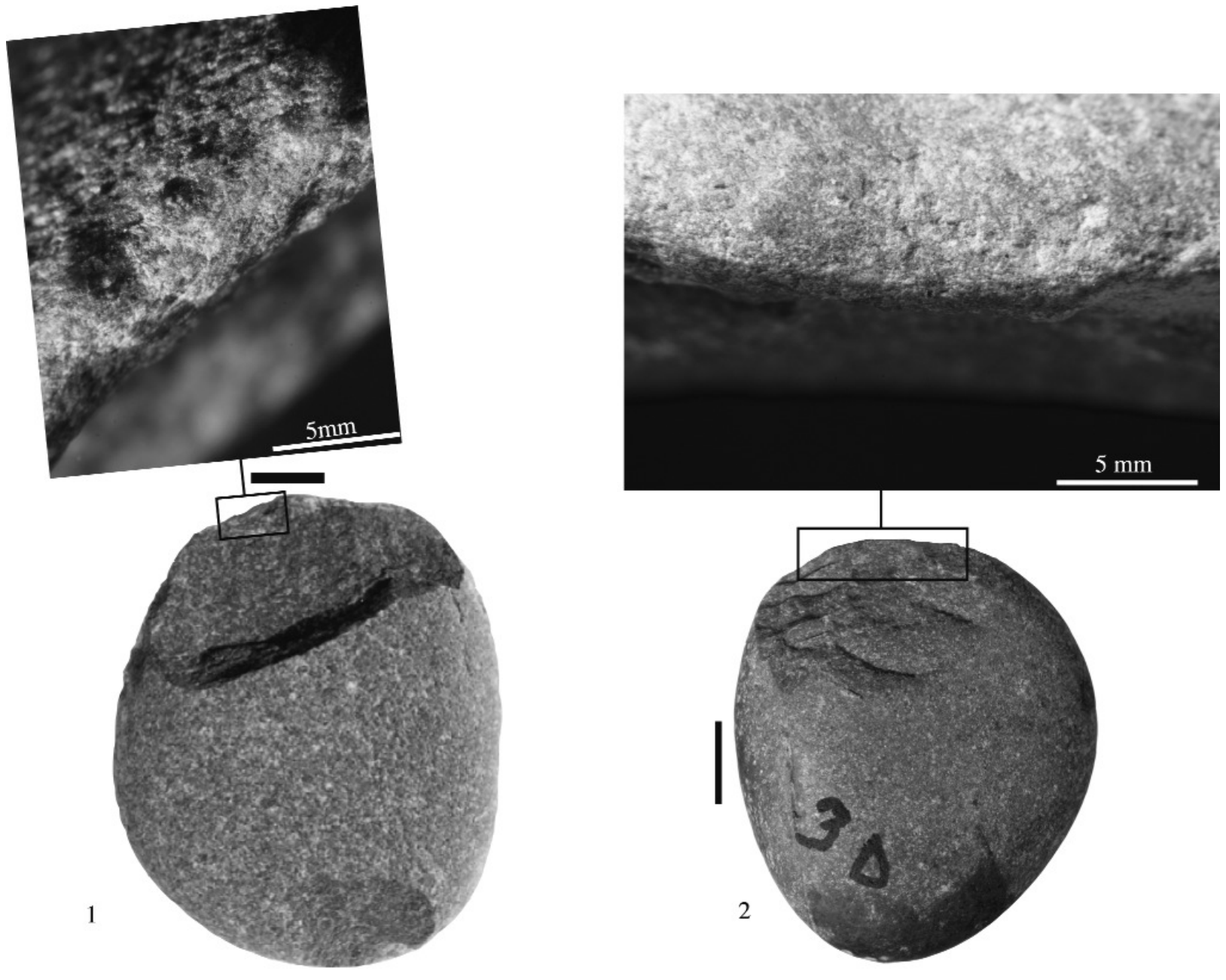

Figure 34 - Percuteurs expérimentaux : 1, percuteur utilisé de nombreuses fois, 2, percuteur utilisé pour la confection de trois denticulés à microdenticulation.

Figure 34 - Experimental hammerstones : 1, hammerstone used many times, 2, hammerstone used to make three microdenticulation denticulates. 
